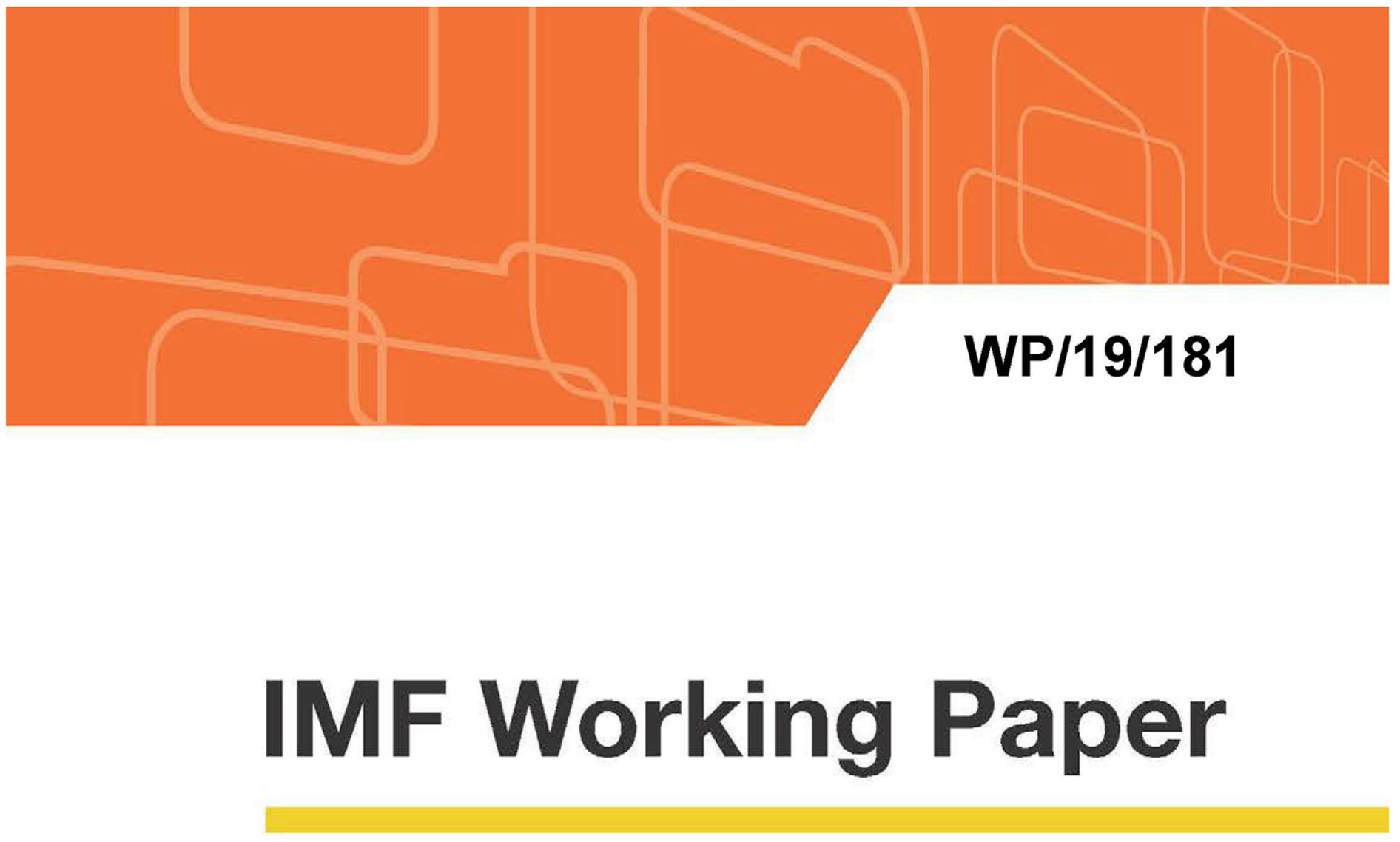

\title{
International Financial Connection and Stock Return Comovement
}

by Sakai Ando

IMF Working Papers describe research in progress by the author(s) and are published to elicit comments and to encourage debate. The views expressed in IMF Working Papers are those of the author(s) and do not necessarily represent the views of the IMF, its Executive Board, or IMF management.

I N T E R N A T I O N A L M O N E T A R Y F U N D 


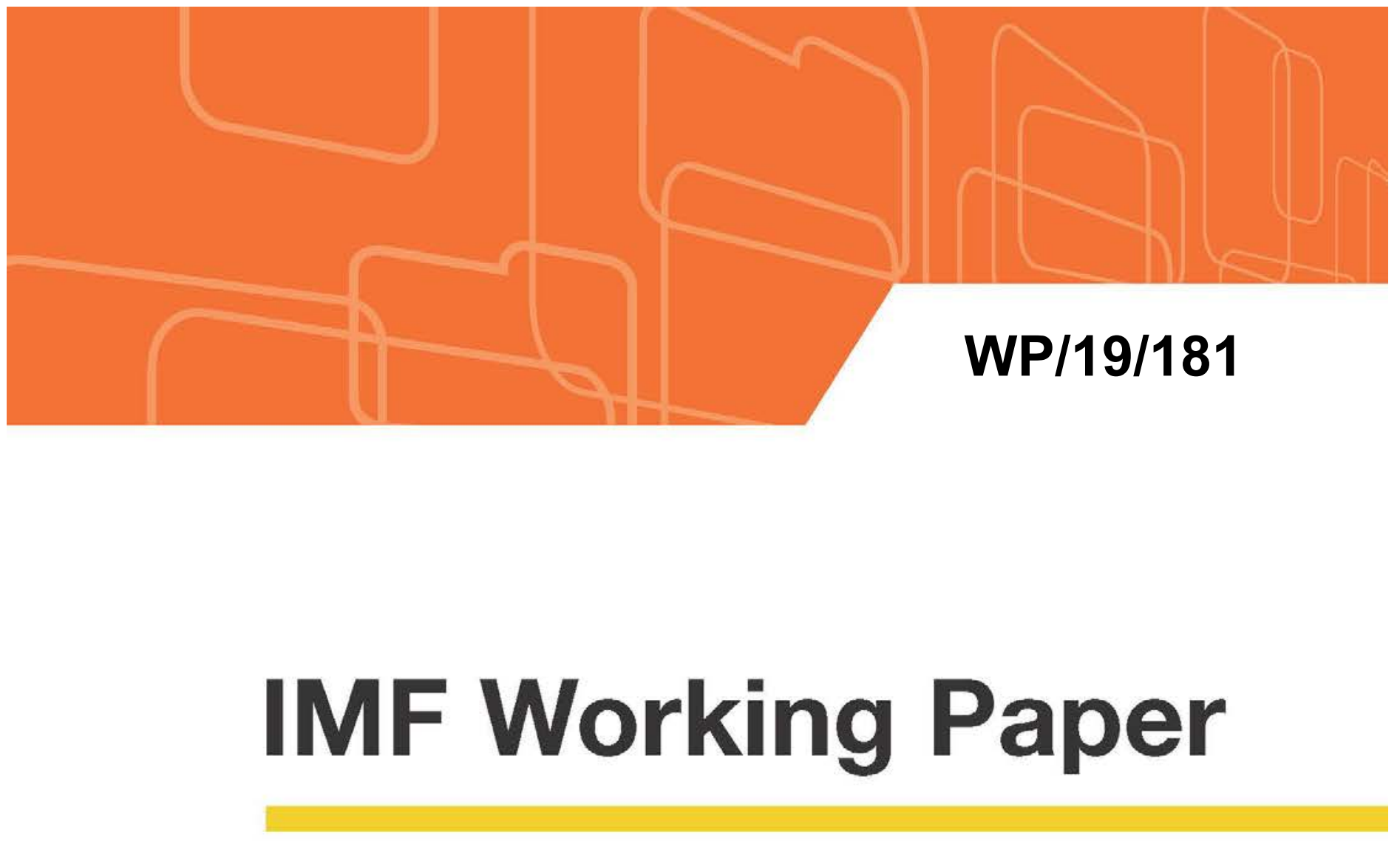

\title{
International Financial Connection and Stock Return Comovement
}

\author{
by Sakai Ando
}

IMF Working Papers describe research in progress by the author(s) and are published to elicit comments and to encourage debate. The views expressed in IMF Working Papers are those of the author(s) and do not necessarily represent the views of the IMF, its Executive Board, or IMF management.

$$
\text { I N T E R N A T I O N A L M O N E T A R Y F U N D }
$$




\title{
IMF Working Paper
}

Statistics Department

\section{International Financial Connection and Stock Return Comovement}

\author{
Prepared by Sakai Ando ${ }^{1}$
}

Authorized for distribution by Paul Austin

August 2019

\section{IMF Working Papers describe research in progress by the author(s) and are published to elicit comments and to encourage debate. The views expressed in IMF Working Papers are those of the author(s) and do not necessarily represent the views of the IMF, its Executive Board, or IMF management.}

\begin{abstract}
This paper studies whether bilateral international financial connection data help predict bilateral stock return comovement. It is shown that, when the United States is chosen as the benchmark, a larger U.S. portfolio investment asset position on the destination economy predicts a stronger stock return comovement between them. For large economies such as the United States and Germany, the portfolio investment position is also the best predictor among other connection variables. The paper discusses with a simple general equilibrium portfolio model that the empirical pattern is consistent with the behavior of index investors who trade in response to risk-on/risk-off shocks.
\end{abstract}

JEL Classification Numbers: F21, F39, G15

Keywords: stock return comovement, international investment position, risk-on, risk-off Author's E-Mail Address: sando@imf.org

\footnotetext{
${ }^{1}$ The author would like to thank Chie Aoyagi, Mitali Das, Selim Ali Elekdag, Robin Koepke, Sheheryar Malik, Akito Matsumoto, Carlos Sánchez-Muñoz, Yannick Timmer, Richard Varghese, Aki Yokoyama, and colleagues in the IMF Statistics Department for helpful discussions and comments. All errors are mine.
} 


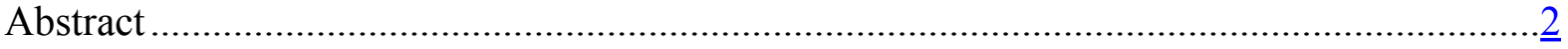

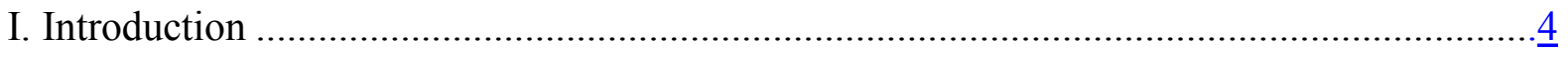

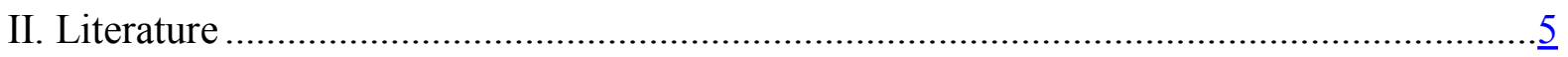

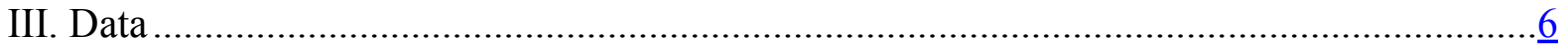

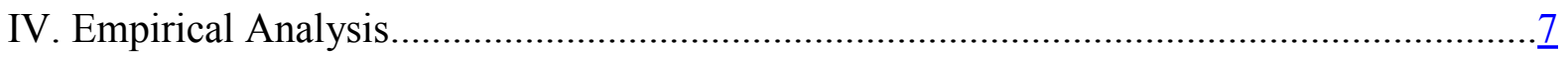

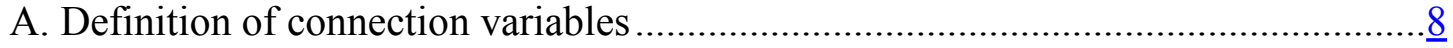

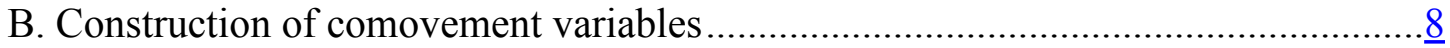

C. Empirical results: the case of the United States .............................................. $\frac{10}{14}$

D. Empirical results: top 20 portfolio investment asset economies..........................14

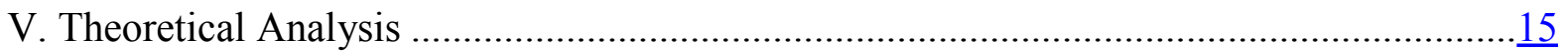

A. A model to rationalize the empirical findings........................................... $\frac{15}{19}$

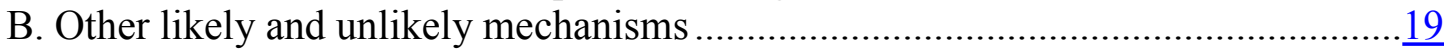

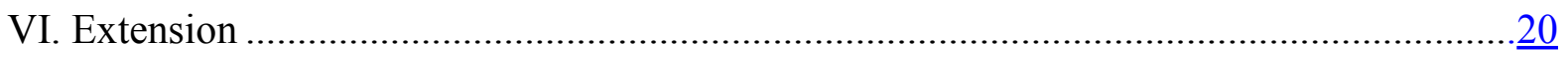

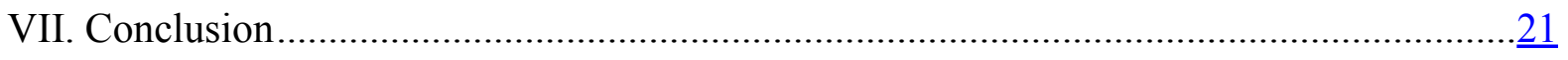

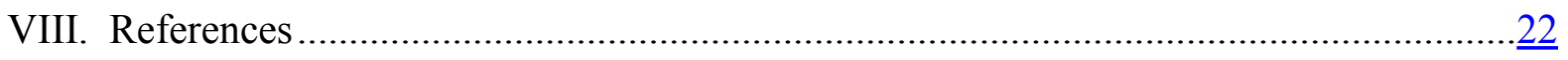

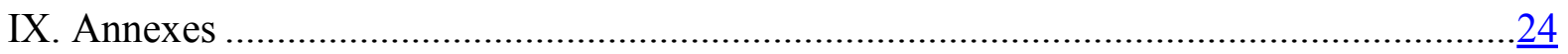

A. Position of the top 20 economies in the four connection databases...................... 24

B. Correlation of U.S. international financial connections .................................... 25

C. Subplots of Figure 1 with ISO2 label for each date .............................................

D. U.S. comovement vs connection, by economy .............................................. $\frac{30}{31}$

E. 5 robustness checks of U.S. Comovement vs Connection ................................... $\frac{31}{33}$

F. Comovement vs Connection, top 6 Rp2 economies............................................

Tables

1. Connection Concepts with Highest Prediction Power ................................................ 15

2. Correlation Matrix of the U.S. International Financial Connections in Log ......................25

Figures

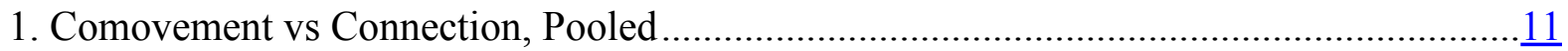

2. Comovement vs Connection, by Date ...................................................................

3. Comovement vs Connection, Alternative Comovement Statistics .................................. $\frac{13}{13}$

4. Comovement vs Connection, Alternative Connection Variable..................................... $\frac{13}{20}$

5. Comovement vs Connection, Government Bond Yield …............................................ 


\section{INTRODUCTION}

The degree of stock return comovement is an important input for many policy applications. For example, to diversify a portfolio, an asset manager needs to know the correlations of stock returns. To simulate a shock propagation scenario, an analyst needs to know the beta coefficient of one stock return index on another. Such degree of comovement, however, is not easy to predict since it can change over time depending on the economic and financial environment.

This paper studies whether financial connection data between two economies help predict the degree of bilateral stock return comovement. Specifically, as indicators of financial connection, this paper explores direct investment positions, portfolio investment positions, bank's balance sheet positions, and trade flows. Intuitively, these connection data might help predict the stock return comovement because they represent the degree of financial integration, which can then contribute to the financial comovement under certain conditions. Although the literature has studied the implications of financial integration on stock return comovement at the global level as summarized in section II, it has not studied bilateral comovement and bilateral connection at the individual economy level.

It is to be noted that the paper analyses prediction capacity and does not address causality. Conceptually, both stock return comovement and international financial connection are endogenous variables, i.e., not exogenous policy variables. Therefore, the question of whether one causes the other is not well-defined in this context.

As the main result, the paper shows that the international financial connection has prediction power on the stock return comovement for large portfolio asset economies. It uses the United States as the benchmark economy and shows that the larger the U.S. portfolio investment asset position on the destination economy is, the more likely that the economy's stock return correlates with the U.S. stock return. Such cross-sectional pattern is stable over time and robust to various specifications. This empirical finding highlights the novel informational contents embedded in the connection data and constitutes the main contribution of this paper.

This finding is apriori non-trivial since, in theory, anything can happen. For example, more connection between economy $A$ and $B$ can be associated with a more negative correlation between them. This can happen if, say, a representative investor in $A$ wants to diversify risks by investing in $B$ 's stock. As $A$ and $B$ 's stock returns correlate more negatively, the representative investor in $A$ might want to increase the position for further diversification. The comovement and connection between $A$ and $B$ can also be independent if there is another economy $C$ that generates shocks by trading stocks in $A$ and $B$.

To assess the strength of the result, the paper studies whether the portfolio investment asset position is the best predictor of the stock return comovement for the United States and whether the same result holds for other economies. Specifically, a horse race of prediction power is conducted for each economy in the sample using all the connection variables. As a complementary result, it is shown that (1) for some of the large asset economies such as the United States or Germany, their portfolio investment asset position vis-à-vis the rest of the economies is indeed the best predictor of the stock return correlation, but (2) for smaller economies, often other connection concepts exhibit a higher prediction power. The result not 
only strengthens the main result about the United States but also highlights the heterogeneity across economies.

A natural question is "what are the mechanisms behind these empirical patterns?" Since the stock return correlation is positively associated with bilateral portfolio investment asset positions, the diversification motive alone cannot rationalize the empirical patterns.

Presumably, there can be many potential mechanisms and they can differ across economies so that it is hard to propose a unified theory that explains all. To make progress, the paper focuses on large portfolio investment asset economies such as the United States and Germany and proposes a simple model that rationalizes the empirical findings. It uses an $N$ country general equilibrium portfolio model to show that the shocks to the risk attitudes can explain that (1) stock returns comove positively as documented in the literature (e.g., Bekaert et al. (2016)) and confirmed in this paper and (2) the degree of stock return comovement can be written as a function of the portfolio investment position.

One can interpret that the model describes the investors who buy and sell index funds in response to risk-on/risk-off shocks. When an investor's risk attitude becomes more risktolerant, the investor increases all the risky positions proportionally. The price impact is larger for the stock in which the investor already has a large position since the one percent increase results in a larger change of the position in the level.

\section{LITERATURE}

The empirical relationship between the stock return comovement and international financial connection has been studied by Forbes and Chinn (2004), which find a weak fit of connection variables despite a rich set of control variables. The analysis has been extended by IMF (2016). These studies pool all the source and destination economies, and therefore, do not allow the connection variable to have heterogeneous explanatory power across economies. Instead of pooling, this paper conducts economy-by economy analyses and find that the connection variables can have a good fit, but the fit can vary across economies. Chuluun (2017) studies whether various centrality measures of the portfolio investment network have explanatory power on the stock return comovement with the world index. Instead of centralities, this paper studies the bilateral position itself and discuss why the bilateral position itself can have a prediction power.

The relationship has also been studied in the theoretical literature of financial integration. Martin and Rey (2000) use a three-country model to analyze the impact of financial integration due to lower transaction cost on asset return. Since, in the model of Martin and Rey (2000), the change in the transaction cost between a pair of economies does not affect other economies asset prices, to explain the comovement across the world, one needs to introduce coordinated shocks to the daily transaction costs of all economies. Evans and Hnatkovska (2014) use a two-country model to rationalize the empirical patterns of international capital flows and financial returns at different stages of financial integration. Instead of comparing the regimes where agents have zero and full access to equity markets, this paper compares different economies in the regime where agents have full access to equity markets.

Stock return comovement and international financial connection have also been studied separately from each other. Bekaert et al. (2016) surveys the literature of globalization and 
asset returns and argue, consistently with this paper, that equity returns are correlated positively and that different classes of asset respond to globalization differently. Diebold and Yilmaz (2009; 2014) and Demirer et al. (2018) use variance decomposition to build a measure of connectedness from stock return data. This paper can be regarded as suggesting an interpretation of the measure of connectedness by showing that the bilateral stock return comovement is informative about the bilateral international financial connection.

There is also a large literature on the international financial connection itself. Lane and Milesi-Ferretti (2008) find bilateral portfolio investment positions are correlated with trade flow and informational proximity. Schiavo et al. (2010) study the topological structure of international financial linkages as well as trade linkages. Kali and Reyes (2010) study the financial contagion on the trade network. Benedictis and Tajoli (2011) use world trade flow to document increasing trade integration. Burger et al. (2018) study the relationship between currency denomination and bond portfolio. These strands of literature study the connection itself and abstract from the analysis of bilateral stock return comovement.

In the context of the business cycle, Kalemli-Ozcan et al (2013) study the effect of financial integration through banks on the transmission of international business cycles. Monnet and Puy (2016) use quarterly GDP data to find international financial integration affects the way countries comove with the rest of the world. This paper complements these analyses by seeing the stock return comovement.

\section{DATA}

This section describes the equity index used to construct stock return comovement and the four databases used to construct international financial connection data.

The stock return comovement data are constructed from Thomson Reuter Global Equity Indices compiled by Refinitiv Datastream. The indices cover 52 stock markets since April 1999 and capture the overall stock price movement by aggregating the 99.5 percent of the market capitalization of the liquid securities in a market. The stock return comovement variables are constructed from the total return index that includes the issuance of dividends. The price index that excludes dividends is used as a robustness check. For the details of the index methodology, see Thomson Reuters (2016).

The financial connection data are constructed from four databases. They are all publicly available and cover 3 out of the 5 functional categories of International Investment Position and the trade account of Balance of Payments with a geographical breakdown. Specifically, the position data cover direct investment, portfolio investment, and other investment. The missing two categories are financial derivatives and reserve assets due to the lack of publicly available data.

Direct investment data are from the Coordinated Direct Investment Survey (CDIS) compiled by the IMF. Direct investment captures the equity and debt investment made by the investors with a significant degree of influence on the receiving entity, defined as holding more than 10 percent share. An exception is loans extended by parent banks to its branches, which is classified as other investment instead of direct investment. The CDIS provides a geographical breakdown of the annual inward and outward direct investment. 
Portfolio investment data are from the Coordinated Portfolio Investment Survey (CPIS) compiled by the IMF. Portfolio investment captures the investment (1) without much influence on the receiving entity, defined as holding less than 10 percent share, but (2) with access to financial markets in the sense that it includes securities traded in financial markets but excludes bank loans and deposits that are not traded in financial markets. The CPIS provides a geographical breakdown of the biannual asset and liability of portfolio investment.

Other investment data are proxied by Locational Banking Statistics (LBS) compiled by the BIS. Other investment includes currency and deposits, loans, and other types of financial positions, capturing the residual of the other 4 functional categories. LBS provides a geographical breakdown of the quarterly claim and liability of banks' balance sheets based on the same definition of residency as CDIS and CPIS.

Trade flow data are from Direction of Trade Statistics (DOTS) compiled by the IMF. DOTS provides the quarterly value of merchandise exports and imports with a geographical breakdown. To maximize the number of samples, export data use "free on board" and import data use "cost, insurance and freight."

To provide a sense of these data, Annex IX.A presents the total external positions of top 20 economies for each connection concept. One can see that the United States is the economy with the largest direct and portfolio investment position, while the United Kingdom has the largest banking sector and China exhibits the largest exports in trade. Table 2 in Annex IX.B presents the correlation matrix of the connection variables for the United States. One can see that all connection data are positively correlated with the correlation being at least 0.6. For further details of the databases, see IMF (2015) for CDIS, IMF (2018) for CPIS, BIS (2013) for LBS, and Marini et al. (2018) for DOTS.

In addition to these data, the paper uses the exchange rate and GDP data from the International Financial Statistics database of the IMF. These are used only for robustness check.

One concern may be the extent to which investments channeled through such financial centers as the Cayman Islands and Luxemburg may bias the results. Although this paper does not attempt to trace back the ultimate source and destination of portfolio investments, it is worth noting that whether those financial centers bias the analysis of this paper depends on the portfolio composition of the capital flows through those financial centers. If the geographical distribution of the indirect capital flows invested via financial centers is substantially different from investments directly routed to their final destination, the empirical results are likely to be biased. Conversely, if the geographical distribution of both direct and indirect capital flows through financial centers are not substantially different, the empirical results remain valid.

\section{EMPIRICAL ANALYSIS}

This section first explains the construction of connection and comovement variables. Then, it shows that the bilateral U.S. portfolio investment asset position vis-à-vis other economies has prediction power on the stock return comovement of those economies with the United States. Finally, it shows that: (1) for large portfolio investment asset economies such as the United States or Germany, those portfolio investment asset positions have the highest prediction 
power on the strength of bilateral stock return comovement among all connection concepts; and (2) for other economies, other connection concepts often have higher prediction power than the portfolio investment asset.

\section{A. Definition of connection variables}

For connection variables, this paper uses the assets and liabilities of the international investment positions and the exports and imports of the trade data. All the variables are quoted in US dollar.

The portfolio investment position serves as the natural benchmark of the connection concept since it includes the positions of the equities that are traded in the stock markets. To explore the benchmark connection in-depth, the analysis includes the equity, total debt, long-term debt, and short-term debt part of the portfolio investment separately in the analysis. Note that the equity part of the portfolio investment does not necessarily capture only the listed stock but can also include investment fund shares whose assets are debts, real estate, or commodities.

Direct investment is also conceptually close to stock return since it contains equity positions of those higher than 10 percent, although some of them are unlisted. Other investment and trade data are not the direct products of stock market transactions, but they can indirectly affect stock return comovement as discussed in section V.

\section{B. Construction of comovement variables}

This section explains the construction of the comovement variables. Ideally, the concept of comovement should capture the similarity of the behaviors of stock returns given the same information during a certain period. In practice, however, there are many choices of the frequency and similarity statistics, and the behavior given the same information is not observable since the markets do not open simultaneously across the world. The rest of the section discusses the frequency, the formula of similarity statistics, and the time adjustment used to construct the comovement variables.

For the frequency, the comovement variables are constructed for each quarter, given that the connection data are at most quarterly. Specifically, the comovement variables are constructed using the trading dates of the following 2 months from the end of each quarter. For example, comovement variables of 2017Q4 are based on 2018 January and February trading-day data. The choice of the period after each quarter is for the prediction purposes and the choice of two-month length is meant to get as close as possible to the date connection variables are recorded, while at the same time, secure enough sample size. The paper also experiments with two months around the end of the quarter, e.g., 2017 December and 2018 January for 2017Q4, and checks that the qualitative result remains the same.

For the formula of comovement variable, this paper uses three statistics to capture the similarity of stock return: correlation, beta, and mean deviation. Formally, let $r_{t}^{i}$ be the rate of stock return of economy $i$ at $t \in \mathcal{T}=\{1, \ldots, T\}$. First, the correlation between economy $A$ and $B$ during $\mathcal{T}$ is defined as the sample correlation coefficient 


$$
\operatorname{corr}\left(r^{A}, r^{B}\right):=\frac{\sum_{t \in \mathcal{T}}\left(r_{t}^{A}-\bar{r}^{A}\right)\left(r_{t}^{B}-\bar{r}^{B}\right)}{\sqrt{\sum_{t \in \mathcal{T}}\left(r_{t}^{A}-\bar{r}^{A}\right)^{2}} \sqrt{\sum_{t \in \mathcal{T}}\left(r_{t}^{B}-\bar{r}^{B}\right)^{2}}}
$$

where $\bar{r}^{i}$ is the sample mean of $r^{i}=\left(r_{t}^{i}\right)_{i \in \mathcal{T}}$. It describes the likelihood of the stock returns moving in the same direction. Second, the mean deviation between economy $A$ and $B$ is defined as

$$
\operatorname{mdev}\left(r^{A}, r^{B}\right):=\frac{1}{T} \sum_{t \in \mathcal{T}}\left|r_{t}^{A}-r_{t}^{B}\right|
$$

It tells the average discrepancy of the return rates. Third, the beta of economy $A$ on $B$ during $\mathcal{T}$ is defined as the regression coefficient $\beta^{A B}$ of

$$
r_{t}^{A}=\alpha^{A B}+\beta^{A B} r_{t}^{B}+\epsilon_{t}, \quad t \in \mathcal{T}
$$

One can interpret it as how much $A$ 's return increases if $B$ 's return increases by 1 percent.

Each of the three statistics has pros and cons and sheds light on different aspects of the comovement. A good property of correlation is that it is normalized by the volatility of returns so is less sensitive to outliers than the other two statistics when projected on connection variables. An undesirable property, however, is that it does not reflect the levels of the return rates, or equivalently the trends of the prices. Put differently, even if one economy has a negative return $r_{t}^{A}>0>r_{t}^{B}$, as long as they fluctuate in the same direction, their correlation can be 1 . The mean deviation can mitigate this problem by reporting a large number when the means of the return rates differ substantially. However, it also has the risk of reporting a small value even when the correlation is -1 just because the means are close. Beta shares the same problem as correlation and is also sensitive to outliers, but it has a natural interpretation of spillover due to its asymmetry $\beta^{A B} \neq \beta^{B A}$.

To build the argument on a robust statistic, this paper uses correlation as the benchmark comovement concept and the other two as complementary statistics. Correlation is not only more robust but also consistent with news media language to describe comovement such as "markets opened lower following falls on the international market." When it comes to the underlying mechanism, however, beta is more compatible with the theoretical analysis. Thus, this paper uses correlation as the empirical benchmark, and the other two as complementary statistics, but draw implications on beta in the theoretical analysis of section V.A.

Finally, the rest of the section describes the adjustments to deal with time lags. As discussed at the beginning of this section, the comovement ideally should capture the stock return behavior given the same information. However, this is not feasible because of the time lag of trading hours.

For the pair of markets that have substantial overlap in trading hours, the same-day stock return data arguably proxies the object of interest. For non-overlapping markets, however, 
using the same-day data is not desirable because it creates an asymmetry in the analysis. For example, in Greenwich Mean Time (GMT), the Tokyo Stock Exchange closes at 6:00 am and the New York Stock Exchange at 8:00 pm. Since the trading hours are less than 7 hours, they do not overlap. If the correlation is calculated using the same-day data, the comovement captures the situation where the information available to the investors in Japan is available to those in the United States, but not vice versa. As a result, the analysis of Japan sees the Granger causality correlation and that of the United States sees the opposite, so the comovement variables are not conceptually consistent across countries.

To mitigate the problem, in the baseline analysis, 1-day lag is taken when the closing time of the stock market in the counterpart economy is more than 7 hours ahead on the same day. For example, when the United States is the benchmark, 1-day lag is taken of the U.S. data to calculate the comovement between the United States and Japan. When Japan is the benchmark, however, no lag is taken for Japan to calculate the U.S.-Japan comovement. Similarly, no lag is taken for the U.S.-U.K. comovement. In this way, the time adjustment allows the comovement variables to proxy the stock return given the same information, and whenever not feasible, consistently capture the comovement when the domestic market closes first.

To assess the robustness of the baseline time adjustment, this paper experiments with two additional time adjustment methods. The first method is to use raw end-of-day data without any adjustment. As discussed above, the disadvantage of this method is the conceptual asymmetry in the analysis. The second is to take the max of lag and current data. For example, when the United States is the benchmark and the correlation between the United Kingdom is of interest, the correlation is calculated using the current United Kingdom and one-day lag of the United States, the current United Kingdom and the current United States, and then choose the max of them. The same is true for the beta, and the max operator, except that the max is replaced by min for mean deviation. This method searches the time convention that maximizes comovement and is convenient when it is hard to identify the economy from which the information that moves stock market emanate. A potential problem is that it can create upward bias in the level of comovement.

Note that it is possible that all the time conventions fail to capture the comovement, for instance, when the source economy of the market-moving information changes every day. Thus, the comovement variables can be systematically downward biased. Thus, the empirical results are conservative and should be interpreted as telling that the connection variables have prediction power even when the comovement variables are captured only partially.

\section{Empirical results: the case of the United States}

This section presents the empirical results of the United States, which is the economy with the largest portfolio asset position. It shows that an economy's daily stock returns tend to comove more with the United States if the United States has a larger portfolio investment asset position on the economy.

The main empirical finding is in Figure 1. Each dot corresponds to a pair of counterpart economy and date. The y-axis is the stock return correlation with the United States and the xaxis is the $\log$ of the U.S. portfolio investment asset. Since all the portfolio investment asset 
data are compiled by the United States, the concerns about inconsistent methodologies or data sources are minimal.

Figure 1. Comovement vs Connection, Pooled

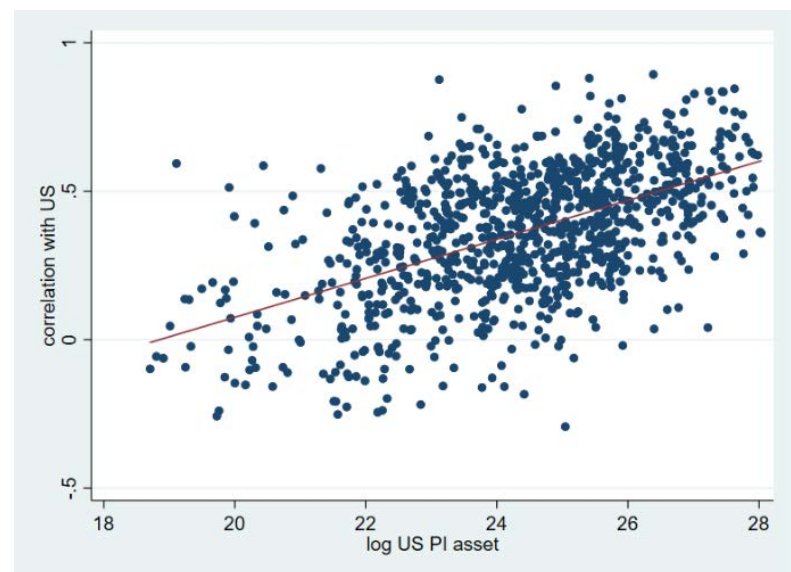

Stock return correlation with the United States vs the log of U.S. portfolio investment asset. Each dot corresponds to a pair of counterpart economy and date. It shows that more international financial connection is associated with more stock return comovement.

Two observations follow from Figure 1. First, comovement is mostly positive. Hence, the typical stock return comovement represents not so much substitution effects that drive prices in the opposite directions between two stock markets as wealth or risk-on/off effects that push prices in the same directions. This positivity of stock return comovement is consistent with the literature (e.g., Bekaert et al. (2016)).

Second, the stock return comovement with the United States is higher when the U.S. portfolio investment asset position on the destination economy is larger. To the best of my knowledge, such observation has not been made in the literature and thus constitutes the main contribution of this paper.

To further understand the finding, the same chart sliced by each date is plotted in Figure 2. It shows that the relationship has been stable over time, despite the fluctuations in both the comovement and connection. Further details of Figure 2 with ISO2 labels are presented in Annex IX.C. One can see that some economies with high correlations, such as Canada, Japan, and the United Kingdom, constantly have large portfolio asset liability to the United States, but the ranking of other economies in connection and comovement change over time.

The chart, however, ceases to exhibit a clear pattern if it is sliced by economy instead of date. The chart is presented in Annex IX.D to ensure its readability, but one can see that, within each economy, the relationship between the comovement and the connection over time is not evident. One potential explanation is that there is a global time fixed effect on stock return comovement such as risk-on/risk-off regimes. When the U.S. portfolio asset fluctuation is smaller than the comovement, the chart sliced by economy can be dominated by the global fixed effects and exhibit a weak relationship. Thus, Figure 1 should be interpreted as a crosssectional relationship rather than time series. 
Figure 2. Comovement vs Connection, by Date

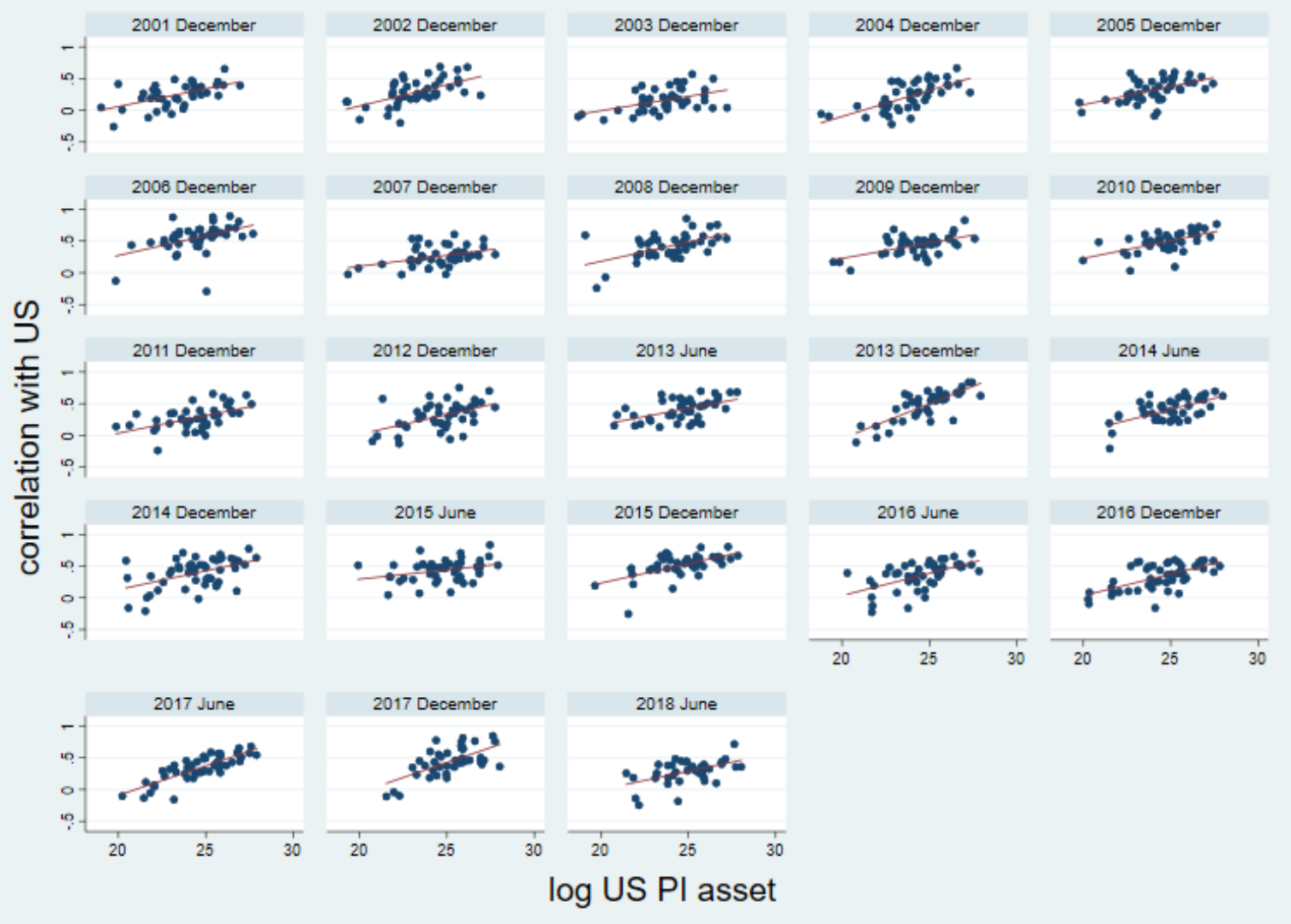

Stock return correlation with the United States vs the log of U.S. portfolio investment asset by CPIS date. It shows that the U.S. portfolio investment asset has had prediction power over time.

To assess the robustness of the finding, Figure 3 shows that the story remains the same if the comovement concept is replaced by the mean deviation (2) and the regression coefficient of the counterpart economy's stock return on the United States (3). Although both charts have some outliers such as Greece crisis periods in 2014 and 2016, one can see that the more connection in the sense of the U.S. portfolio investment asset is associated with more stock return comovement.

Annex IX.E presents 5 additional robustness checks and show that the relationship still holds (1) after considering daily FX return, (2) after normalizing the position by the GDP of the counterpart economy, (3) if the connection variable is replaced by portfolio equity position or portfolio debt position, (4) if the stock index is replaced by the price index that excludes dividends, and (5) if the benchmark time adjustment is replaced by the other two methods discussed in section IV.B. The main takeaway is that, under various specifications, one can see that the daily stock returns tend to comove more with the United States for those economies with stronger international financial connection with the United States. 
Figure 3. Comovement vs Connection, Alternative Comovement Statistics
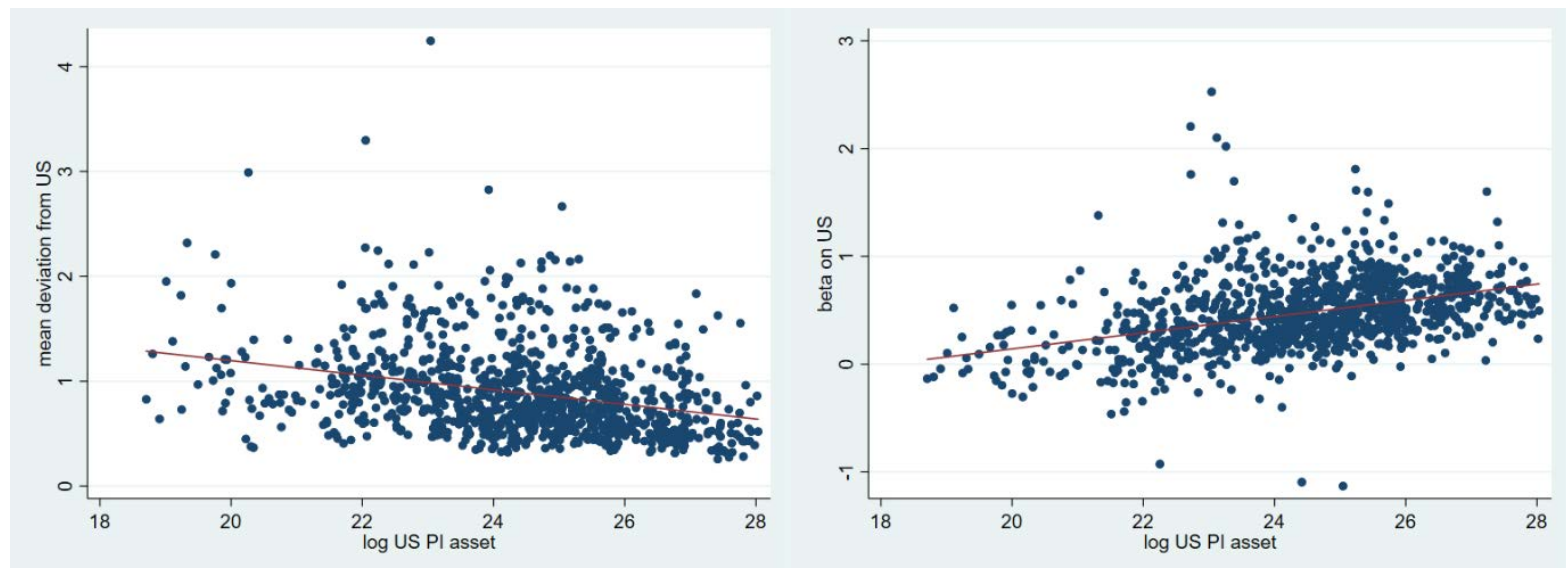

The left chart shows the median deviation between the stock return of the counterpart economy and that of the United States vs the log of U.S. portfolio investment asset. Each dot corresponds to a pair of counterpart economy and date. The right chart shows the regression coefficient of the stock return of the counterpart economy on that of the United States. Both charts show that more international financial connection is associated with more stock return comovement.

The relationship, however, is not always evident if the connection variable is not the portfolio investment asset position. For example, Figure 4 shows that the predictability of the connection variable becomes less evident if the portfolio investment asset is replaced by bank asset divided by the counterpart economy's GDP. This observation naturally generates the question "which connection concept predicts the stock return comovement best for each economy?" The next section addresses this question.

\section{Figure 4. Comovement vs Connection, Alternative Connection Variable}

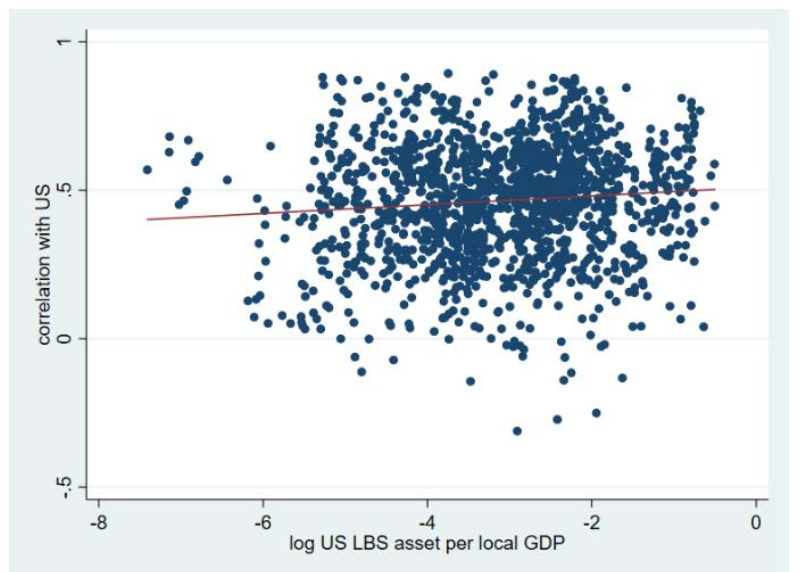

Stock return correlation with the United States vs the log of U.S. bank asset per the GDP of the counterpart economy. Each dot corresponds to a pair of counterpart economy and date. It shows that the international financial connection does not have an obvious prediction power on the stock return comovement. 


\section{Empirical results: top 20 portfolio investment asset economies}

This section defines the criteria of prediction power and runs a horse race with all the connection concepts. It shows that, for some of the large portfolio investment asset economies such as the United States and Germany, portfolio investment asset is the best predictor of the stock return comovement, but for other economies, different connection concepts often predict better.

To measure the prediction power in an intuitive unit, this paper uses R-square and leave-oneout pseudo R-square, denoted respectively by $R^{2}$ and $R_{p}^{2} \cdot R^{2}$ can be interpreted as the percentage of the variations in stock return comovement explained by a linear function of the connection variable, while $R_{p}^{2}$ as the magnitude of the correlation between the fitted value and actual value.

Specifically, for $R^{2}$, the comovement variable $y_{e t}$ is regressed on a connection variable $x_{e t}$ and time fixed effects,

$$
R^{2}=\frac{\sum_{e, t}\left(\hat{y}_{e t}-\bar{y}\right)^{2}}{\sum_{e, t}\left(y_{e t}-\bar{y}\right)^{2}}, \quad \hat{y}_{e t}=\sum_{t^{\prime}} \hat{\alpha}_{t^{\prime}} 1_{t=t^{\prime}}+x_{e t} \hat{\beta},
$$

where $e$ denotes the counterpart economy, $t$ denotes date, and $\bar{y}$ denotes the mean of comovement $\left\{y_{e t}\right\}_{e, t}$. The time effects absorb the variation that affects the level of comovement, and therefore, allows me to combine data from all dates and search the connection variable with stable slope over time.

$R_{p}^{2}$ is calculated from the same regression but the fitted value of $y_{e t}$ does not use sample $(e, t)$. Formally, let $\left(\left\{\hat{\alpha}_{-e, t}\right\}_{t^{\prime}} \hat{\beta}_{-e}\right)$ be the regression coefficients generated by the leave-oneout regression. $R_{p}^{2}$ is defined as

$$
R_{p}^{2}=\left\{\operatorname{corr}\left(\hat{y}^{p}, y\right)\right\}^{2}, \quad \hat{y}_{e t}^{p}=\sum_{t^{\prime}} \hat{\alpha}_{-e, t} 1_{t=t^{\prime}}+x_{e t} \hat{\beta}_{-e} .
$$

$R_{p}^{2}$ can be considered a legitimate prediction criterion since (1) the comovement variables are recorded after the connection variables and (2) the prediction of each observation is based on the leave-one-out method.

Note that the objective of the regression is neither parameter estimation nor causality. Thus, the statistical significance of the regression coefficients are not of interest and the model does not include controls. In the context of this paper, the statistical errors based on the i.i.d. assumption is not informative since all the observations in each regression reflect the decision making of the single source economy. The causality is also not well-defined since both the comovement and connection variables are endogenous variables.

Table 1 summarizes the connection concept with the highest prediction power for each economy in the order of $R_{p}^{2}$. Each economy is represented by ISO2 code. PI, DI, LTD, and 
STD denote portfolio investment, direct investment, long-term debt, and short-term debt respectively. Annex IX.F presents the charts of the top $6 R_{p}^{2}$ economics.

Table 1. Connection Concepts with Highest Prediction Power

\begin{tabular}{|c|c|c|c|c|}
\hline Economy & Highest $R^{2}$ (in log) & $R^{2}$ & Highest $R_{p}^{2}$ (in log) & $R_{p}^{2}$ \\
\hline \hline DE & PI asset & 0.58 & PI asset & 0.57 \\
\hline AT & PI asset & 0.57 & PI asset & 0.55 \\
\hline BE & PI asset & 0.57 & PI asset & 0.55 \\
\hline CH & DI inward & 0.58 & DI inward & 0.54 \\
\hline CN & Bank's liability & 0.58 & Bank's liability & 0.54 \\
\hline IT & PI asset & 0.56 & PI asset & 0.54 \\
\hline NL & Export & 0.55 & Export & 0.53 \\
\hline FR & PI asset (LTD) & 0.55 & PI asset (LTD) & 0.53 \\
\hline ES & PI asset (LTD) & 0.56 & PI asset (LTD) & 0.52 \\
\hline FI & PI asset (STD) & 0.55 & PI asset (LTD) & 0.51 \\
\hline DK & Bank's asset & 0.56 & PI asset (STD) & 0.51 \\
\hline SE & Import & 0.50 & Import & 0.48 \\
\hline IE & PI liability (LTD) & 0.49 & PI liability (LTD) & 0.46 \\
\hline CA & DI outward & 0.47 & PI asset (LTD) & 0.45 \\
\hline GB & PI asset (LTD) & 0.47 & PI asset (LTD) & 0.44 \\
\hline US & PI asset & 0.45 & PI asset & 0.43 \\
\hline SG & Bank's liability & 0.46 & Bank's asset & 0.40 \\
\hline HK & DI outward & 0.48 & Bank's asset & 0.34 \\
\hline JP & DI outward & 0.34 & DI outward & 0.30 \\
\hline KR & Bank's liability & 0.37 & Bank's liability & 0.29 \\
\hline
\end{tabular}

Two observations follow from Table 1. First, $R^{2}$ and $R_{p}^{2}$ tend to point to the same connection concept and give similar a number. Since they are conceptually different, one can interpret the coincidence as the result's robustness. Second, portfolio investment asset is not always the best predictor. This observation suggests that different economies have different structures so the most relevant connection concept for prediction purpose differs across economies. The next section discusses potential mechanisms behind the empirical results.

\section{Theoretical Analysis}

The previous section has shown that the stock returns tend to comove more when the economies are more financially connected. There can be many underlying mechanisms that generate such patterns, and they can vary across economies and over time. Instead of aiming at one unified theory that explains all of them, this paper focuses on the large portfolio investment economies such as the United States and Germany and propose one simple model that rationalizes the empirical finding. This section also discusses other potential mechanisms.

\section{A. A model to rationalize the empirical findings}

This section presents a model that rationalizes Figure 1 and Figure 3. Specifically, the model explains (1) why comovement tends to be positive and (2) why the portfolio investment 
position contains informational contents for the prediction of stock return comovement. The model is an extension of Grossman and Stiglitz (1980) to $N$ economies and generates both the comovement and connection variables endogenously.

There are $N$ economies. Each economy $i=1, \ldots, N$ has a representative investor $i$ and a stock market in which investors can trade a representative stock with random return $d_{i}$ for price $p_{i}$. Let $d=\left[d_{1}, \ldots, d_{N}\right]^{\prime}$ denote the vector of random return. Investor $i$ believes that the return $d$ is distributed according to $d \sim N\left(\bar{\mu}_{i}, \Omega\right)$. Note that investors' beliefs are not restricted to be a common prior so that $\bar{\mu}_{i}$ can differ from $\bar{\mu}_{j}$. The heterogeneous beliefs generalize the model to allow an arbitrary portfolio investment position in equilibrium.

The preference of the representative investor $i$ is assumed to be Constant Absolute Risk Aversion (CARA). Given the economy-specific risk-free rate $R_{i}$, risk tolerance $\tau_{i}$, wealth $\omega_{i}$, and the stock price $p=\left[p_{1}, \ldots, p_{N}\right]^{\prime}$, the representative investor $i$ chooses the portfolio of risky assets $x_{i}=\left[x_{i 1}, \ldots, x_{i N}\right]^{\prime}$ to maximize

$$
U_{i}\left(x_{i}, p\right)=\mathbb{E}_{i}\left[-\exp \left[-\frac{1}{\tau_{i}}\left\{\sum_{j=1}^{N}\left(d_{j}-p_{j}\right) x_{i j}+R_{i}\left(\omega_{i}-\sum_{j=1}^{N} p_{j} x_{i j}\right)\right\}\right] \mid p\right]
$$

The normality assumption and exponential preference reduce the model into CARA normal structure, and therefore, allow a clean analysis in closed form. One disadvantage of the CARA normal structure is that it does not directly allow the wealth effect. One way to naturally incorporate the wealth effect is to allow the risk tolerance to be a function of wealth $\tau_{i}\left(\omega_{i}\right)$. One advantage of CARA normal structure is that the composition of the portfolio investment is constant with respect to the risk attitude. This property allows the interpretation of passive traders who trade index funds in response to shocks to risk attitude.

The total supply of the stock in economy $i$ is denoted by $X_{i}$. Let $X=\left[X_{1}, \ldots, X_{N}\right]^{\prime}$ denote the vector of stock supply. The equilibrium is defined as follows.

Definition. Stock price $p^{*}$ is an equilibrium if it satisfies

1. Given price $p^{*}$, each representative investor $i$ solves

$$
x_{i}\left(p^{*}\right)=\arg \max _{x_{i}} U_{i}\left(x_{i}, p^{*}\right) .
$$

2. Stock markets clear

$$
\sum_{i=1}^{N} x_{i}\left(p^{*}\right)=X
$$

The interpretation of daily stock return should be noted with care in this two-period model. The random return $d$ represents the long-run value of the stock and shape the portfolio investment position $x_{i}$ for each investor $i$. However, what affects daily stock return is not the 
long run value $d$ but is the shocks that hit the risk tolerance $\tau_{i}$. In other words, the daily return $\partial \ln p^{*} / \partial \tau_{i}$ is generated from a shock to risk attitude $\partial \tau_{i}$ that is an observable but unpredictable surprise to investors.

In this framework, it can be shown that the degree of comovement originating from shocks to risk attitude can be written as a function of the portfolio investment position.

Proposition. Let $x_{i}^{*}:=x_{i}\left(p^{*}\right)$ be the equilibrium portfolio. Suppose a risk tolerance shock hits economy $i$. Then, the degree of comovement $\beta_{i j}$ takes the following form

$$
\frac{\partial p_{j}^{*}}{\partial \tau_{i}}=\beta_{i j} \frac{\partial p_{i}^{*}}{\partial \tau_{i}}, \quad \beta_{i j}:=\frac{\sum_{k=1}^{N} \Omega_{j k} x_{i k}^{*}}{\sum_{k=1}^{N} \Omega_{i k} x_{i k}^{*}} .
$$

Proof. Recall that if $X \sim N\left(\mu_{X}, \sigma_{X}^{2}\right)$,

$$
\mathbb{E} e^{X}=e^{\mu_{X}+\frac{1}{2} \sigma_{X}^{2}}
$$

With vector notation,

$$
\begin{aligned}
U_{i}\left(x_{i}, p\right) & =\mathbb{E}_{i}\left[-\exp \left[-\frac{1}{\tau_{i}}\left\{(d-p)^{\prime} x_{i}+R_{i}\left(\omega_{i}-p^{\prime} x_{i}\right)\right\}\right] \mid p\right] \\
& \approx\left\{\bar{\mu}_{i}-\left(1+R_{i}\right) p\right\}^{\prime} x_{i}-\frac{1}{2 \tau_{i}} x_{i}^{\prime} \Omega x_{i}
\end{aligned}
$$

By solving the first order condition,

$$
x_{i}(p)=\Omega^{-1}\left(\mu_{i}-p\right) w_{i}, \quad \mu_{i}:=\frac{\bar{\mu}_{i}}{1+R_{i}}, \quad w_{i}:=\tau_{i}\left(1+R_{i}\right)
$$

The market clearing condition gives the equilibrium price

$$
p^{*}=\frac{1}{W}\left(\sum_{k=1}^{N} w_{k} \mu_{k}-\Omega X\right), \quad W=\sum_{k=1}^{N} w_{k}
$$

The associated equilibrium position is

$$
x_{i}^{*}:=x_{i}\left(p^{*}\right)=\Omega^{-1}\left\{\sum_{k=1}^{N} \frac{w_{k}}{W}\left(\mu_{i}-\mu_{k}\right)+\frac{1}{W} \Omega X\right\} w_{i}
$$

One can use the market clearing condition to obtain the derivative of the equilibrium price $p^{*}$ with respect to the risk tolerance $\tau_{i}$. 


$$
\frac{\partial p^{*}}{\partial \tau_{i}}=\left(\mu_{i}-p^{*}\right) \frac{1}{W} \frac{\partial w_{i}}{\partial \tau_{i}}=\Omega x_{i}^{*} \frac{1}{W w_{i}} \frac{\partial w_{i}}{\partial \tau_{i}}
$$

where the last equality follows from Eq. (5). Dividing the $j$ th element by the $i$ th leads to

$$
\frac{\partial p_{j}^{*}}{\partial \tau_{i}}=\frac{\sum_{k=1}^{N} \Omega_{j k} x_{i k}^{*}}{\sum_{k=1}^{N} \Omega_{i k} x_{i k}^{*}} \frac{\partial p_{i}^{*}}{\partial \tau_{i}}
$$

The proposition claims that the comovement between the two economies $i$ and $j$ due to the risk tolerance shock to investor $i$ can be written as a function of $i$ 's asset positions $\left\{x_{i k}^{*}\right\}_{k}$. One can see from Eq. (5) that the comovement is larger $\beta_{i j}>\beta_{i j^{\prime}}$ when investor $i$ has more positive belief $\mu_{i j}-p_{j}>\mu_{i j^{\prime}}-p_{j^{\prime}}>0$. The order of belief and the position coincide when the return is i.i.d., i.e., $\Omega=\sigma^{2} I_{N \times N}$ for some $\sigma>0$, in which case the beta is simply the ratio of $i$ 's position on $j$ over $i$ 's position on $i$

$$
\frac{\partial p_{j}^{*}}{\partial \tau_{i}}=\frac{x_{i j}^{*}}{x_{i i}^{*}} \frac{\partial p_{i}^{*}}{\partial \tau_{i}}
$$

Intuitively, when the representative investor's risk tolerance increases, it increases the size of the portfolio proportionally across all stocks. The one percent increase has a bigger price impact on the economies in which the representative investor $i$ already has a large position. Thus, the shocks to risk attitude of U.S. investors can explain both (1) the positive comovement and (2) stronger comovement as the connection gets stronger in the beta chart of Figure 3.

The proposition, however, is based on a single shock. Such a single shock cannot explain Figure 1 since the correlation will be either 1 or -1 irrespective of the portfolio investment position. One can rationalize Figure 1 in the current framework by allowing shocks to hit all investors. To illustrate the intuition, suppose all risk tolerance $\left\{\tau_{i}\right\}_{i=1}^{N}$ are non-degenerate i.i.d. random variables and for simplicity $X=0$ and $\Omega=I$. From Eq. (6), the equilibrium price is a weighted sum of the investors' beliefs

$$
p=\sum_{k=1}^{N} \frac{w_{k}}{W} \mu_{k}
$$

One can see that for any pair of prices $\left(p_{i}, p_{j}\right)$, their correlation can take an arbitrary number between -1 and 1 if the beliefs $\left\{\mu_{k i}, \mu_{k j}\right\}_{k=1}^{N}$ are appropriately chosen.

Higher correlation and higher investment position as in Figure 1 can be achieved simultaneously by increasing the belief parameters. To see this, suppose investor $i$ highly values home economy $i$ and economy $j$, i.e., $\mu_{i i} \gg \mu_{k i} \geq 0$ and $\mu_{i j} \gg \mu_{k j} \geq 0$ for all $k \neq i$. By zooming into the $i$ and $j$ th element of the price vector, one can see that the price fluctuations are mainly driven by the shocks to $i$ 's risk attitude $\tau_{i}$, or equivalently $\frac{w_{i}}{W}$, 


$$
p_{i}=\frac{w_{i}}{W} \mu_{i i}+\sum_{k \neq i}^{N} \frac{w_{k}}{W} \mu_{k i}, \quad p_{j}=\frac{w_{i}}{W} \mu_{i j}+\sum_{k \neq i}^{N} \frac{w_{k}}{W} \mu_{k j}
$$

Accordingly, the correlation between the two prices increases. The position also increases since $x_{i j}$ is an increasing function of $\mu_{i j}$, as can be seen by combining Eq. (5). and (6).

$$
x_{i j}=\left(\frac{W-w_{i}}{W} \mu_{i j}-\sum_{k \neq i}^{N} \frac{w_{k}}{W} \mu_{k j}\right) w_{i} .
$$

Intuitively, when investor $i$ has a high valuation in $i$ and $j$ 's stocks, $i$ 's portfolio investment position on $j$ is large, and the two prices mostly reflect investor $i$ 's preference and shocks on it. Thus, the shocks to risk attitudes of all the investors can explain Figure 1 when investors have strong beliefs on home and the destination economies.

\section{B. Other likely and unlikely mechanisms}

Although the previous section V.A provides a model consistent with the empirical patterns, there can be many other mechanisms. The potential mechanisms may also vary across economies as suggested by Table 1 . This section discusses other potential mechanisms. To make the argument more comprehensive, this section also discusses some unlikely mechanisms.

In theory, any of the international financial connection variables can have prediction power on stock return comovement. In fact, since all the connection variables are correlated as shown in Table 2 in Annex IX.B, it is possible that all of them play important roles.

For instance, one can tell a reasonable story about why direct investment liability can predict the stock return comovement. Imagine that a car company $a$ in economy $A$ creates a subsidiary $b$ in $B$. Investors might expect that the performance of company $a$ depends on the sales of the subsidiary in $B$. One way for them to estimate the sales is to use $b$ 's stock information in $B$. If investors buy and sell $a$ 's stock in the stock market of $A$ based on $B$ 's stock market information, the stock returns naturally comove. Such comovement would be stronger if the company $a$ has a larger direct investment position in $B$ because it has a larger exposure to $B$.

It is also not surprising if bank liability predicts the stock return comovement. A bank $a$ in economy $A$ can grant loans to their subsidiaries, other banks, and non-financial projects in $B$. It is then natural for investors to use $B$ 's stock information as one of the variables to predict the performance of the bank $a$ and other affected industries. As the exposure increases, investors naturally become more sensitive to $B$ 's stock data.

Although there can be many other mechanisms behind the empirical findings and it is not easy to narrow down to a unique story, some mechanisms can be excluded. For example, diversification motive alone is not likely to drive the empirical result. If everything else is equal, to diversify the portfolio, investors need to invest in the economy that exhibits a 
negative correlation with the home economy. This point shares the same flavor as the international diversification puzzle. ${ }^{2}$

The empirical results are not likely, if at all possible, to be driven by pure sentiment or statistical errors. It is not hard to use sentiments to explain positive comovement but linking stronger sentiments to larger positions can be challenging. Similarly, if statistical errors in international financial connections are random, it would be probabilistically rare to observe that they are proportional to the daily stock return.

\section{EXTENSION}

The empirical exercise can be extended in several dimensions. This section discusses an extension of bond yields and its limitations. It also discusses the potential use of more granular connection data.

The analysis of stock return comovement can be naturally extended to other asset classes. For example, equity return can be replaced by bond yields change. Figure 5 shows the same plots with equity replaced by 3 -month and 10 -year government bond yields. Since the yields are already in percent, the change from the previous trading date is used instead of the rate of return.

One can see that the behaviors are substantially different for the two maturities. The shortterm bond yields in the left chart show almost no relationship with the U.S. portfolio asset position, while the long-term bond yields in the right chart show an increasing pattern. The charts look similar if asset positions are replaced by liability positions.

\section{Figure 5. Comovement vs Connection, Government Bond Yield}
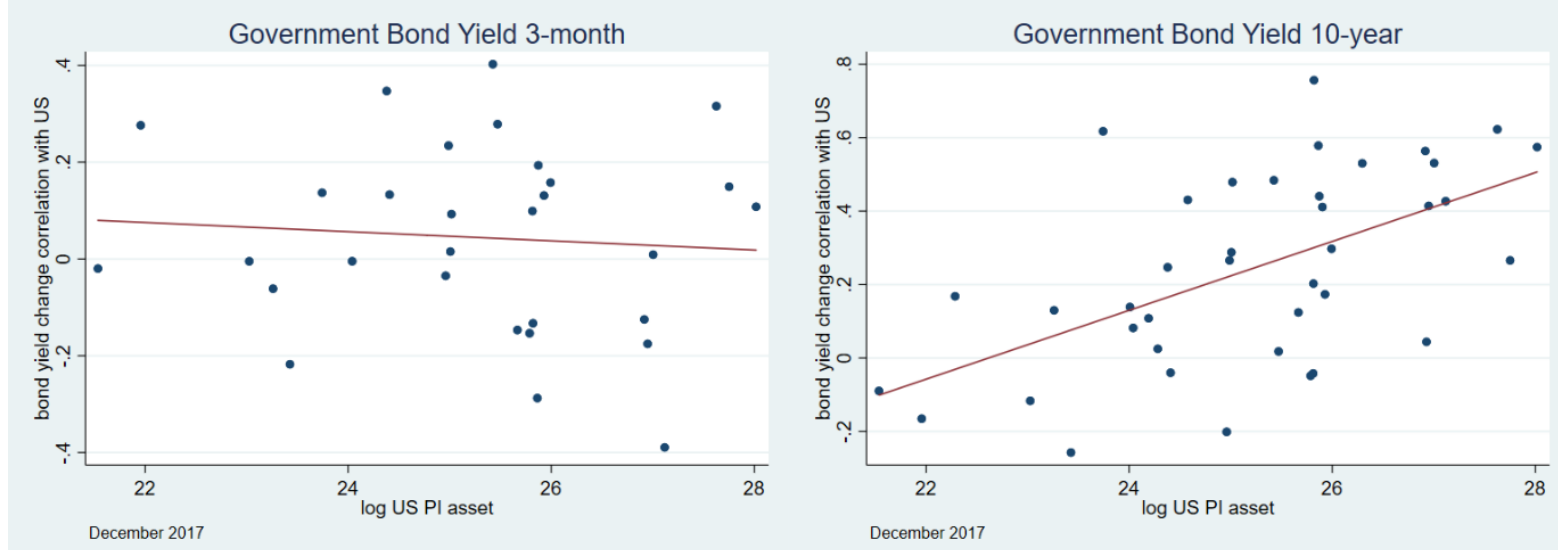

Correlation of daily government bond yield change vs log U.S. portfolio asset in December 2017. The left chart is 3-month and the right chart is 10-year bond. It shows that the U.S. portfolio asset positions have different prediction power for different maturity.

\footnotetext{
${ }^{2}$ For the discussion of international diversification puzzle, see for example, Baxter and Jermann (1997), Engel and Matsumoto (2009), and Heathcote and Perri (2013).
} 
There are several reasons, however, for which the analysis of government bond yields is less informative than that of stock returns. One reason is that government bonds are often classified in confidential reserve assets and therefore do not show up in portfolio investment or direct investment data. This is particularly true for short term bonds. Another reason is that the yields of government bonds are often the direct policy instruments, so the changes in yields may reflect different forces than the profit-maximizing motive that drive equity markets. These caveats should be noted in interpreting the bond comovement.

Another extension that can be potentially useful is to explore further granularity of the connection data. Since equity indices are often available for each industry, if the connection data have a further breakdown at the industry level, or more realistically at the institutional sector level, the stock return analysis can be extended from country level to country-sector level. Such from-whom-to-whom data are available in CPIS table 6 for 16 economies as of June 2018. ${ }^{3}$ The additional granularity can be used to further narrow down the analysis of stock return comovement.

\section{CONCLUSION}

This paper has shown that a stronger international financial connection is associated with a stronger stock return comovement. Taking some of the large portfolio investment asset economies such as the United States or Germany as the benchmark, bilateral portfolio positions have the highest prediction power. For other smaller economies, the best predictor varies. This paper has also proposed a general equilibrium portfolio theory that is consistent with the empirical patterns. The empirical finding is supportive of the intuition that a more connected world tends to have more comovement, but it also highlights that the meaning of connection might differ across countries.

The findings in this paper can have several policy applications. As discussed in Section I, stock return comovement is an important input for the diversification of portfolio and spillover analysis. One can also reversely use stock return comovement to estimate the international financial connection. Exploring these applications are left for future research.

\footnotetext{
${ }^{3}$ See Harutyunyan and Sánchez-Muñoz (2019) for further details about the collection of from-whom-to-whom portfolio data.
} 


\section{REFERENCES}

Baxter, M., \& Jermann, U. J. (1997). The International Diversification Puzzle Is Worse Than You Think. The American Economic Review, 87, 170-180.

Bekaert, G., Harvey, C. R., Kiguel, A., \& Wang, X. (2016, 10). Globalization and Asset Returns. Annual Review of Financial Economics, 8, 221-288.

Benedictis, L. D., \& Tajoli, L. (2011). The World Trade Network. The World Economy, 34, 1417-1454.

BIS. (2013). Reporting guidelines and practices for BIS international banking statistics.

Burger, J. D., Warnock, F. E., \& Warnock, V. C. $(2018,9)$. Currency matters: Analyzing international bond portfolios. Journal of International Economics, 114, 376-388.

Chuluun, T. (2017, 5). Global portfolio investment network and stock market comovement. Global Finance Journal, 33, 51-68.

Demirer, M., Diebold, F. X., Liu, L., \& Yilmaz, K. (2018). Estimating global bank network connectedness. Journal of Applied Econometrics, 33, 1-15.

Diebold, F. X., \& Yilmaz, K. (2009). Measuring Financial Asset Return and Volatility Spillovers, with Application to Global Equity Markets*. The Economic Journal, 119, 158-171.

Diebold, F. X., \& Y1lmaz, K. (2014, 9). On the network topology of variance decompositions: Measuring the connectedness of financial firms. Journal of Econometrics, 182, 119-134.

Engel, C., \& Matsumoto, A. (2009, 7). The International Diversification Puzzle When Goods Prices Are Sticky: It's Really about Exchange-Rate Hedging, Not Equity Portfolios. American Economic Journal: Macroeconomics, 1, 155-188.

Evans, M. D., \& Hnatkovska, V. V. (2014, 1). International capital flows, returns and world financial integration. Journal of International Economics, 92, 14-33.

Forbes, K. J., \& Chinn, M. D. (2004). A Decomposition of Global Linkages in Financial Markets over Time. The Review of Economics and Statistics, 86, 705-722.

Grossman, S. J., \& Stiglitz, J. E. (1980). On the Impossibility of Informationally Efficient Markets. The American Economic Review, 70, 393-408.

Harutyunyan, A., \& Sánchez-Muñoz, C. (2019). The IMF balance sheet approach: towards from-whom-to-whom information on cross-border portfolio securities. In IFC

Bulletins chapters (Vol. 49). Bank for International Settlements.

Heathcote, J., \& Perri, F. (2013). The International Diversification Puzzle Is Not as Bad as You Think. Journal of Political Economy, 121, 1108-1159.

IMF. (2015). The Coordinated Direct Investment Survey Guide 2015. USA: IMF eLibrary.

IMF. (2016). Global Financial Stability Report, April 2016 : Potent Policies for a Successful Normalization.

IMF. (2018). Coordinated Portfolio Investment Survey Guide (Third Edition). USA: IMF eLibrary.

Kalemli-Ozcan, S., Papaioannou, E., \& Perri, F. (2013, 3). Global banks and crisis transmission. Journal of International Economics, 89, 495-510.

Kali, R., \& Reyes, J. (2010). Financial Contagion on the International Trade Network. Economic Inquiry, 48, 1072-1101.

Lane, P. R., \& Milesi-Ferretti, G. M. (2008, 7). International Investment Patterns. The Review of Economics and Statistics, 90, 538-549.

Marini, M., Dippelsman, R., \& Stanger, M. (2018). New Estimates for Direction of Trade Statistics. 
Martin, P., \& Rey, H. (2000, 6). Financial integration and asset returns. European Economic Review, 44, 1327-1350.

Monnet, E., \& Puy, D. (2016). Has Globalization Really Increased Business Cycle Synchronization? IMF Working papers.

Schiavo, S., Reyes, J., \& Fagiolo, G. (2010, 4). International trade and financial integration: a weighted network analysis. Quantitative Finance, 10, 389-399.

Thomson Reuters Global Equity Indices Index Methodology. (2016). Thomson Reuters. 


\section{ANNEXES}

\section{A. Position of the top 20 economies in the four connection databases}
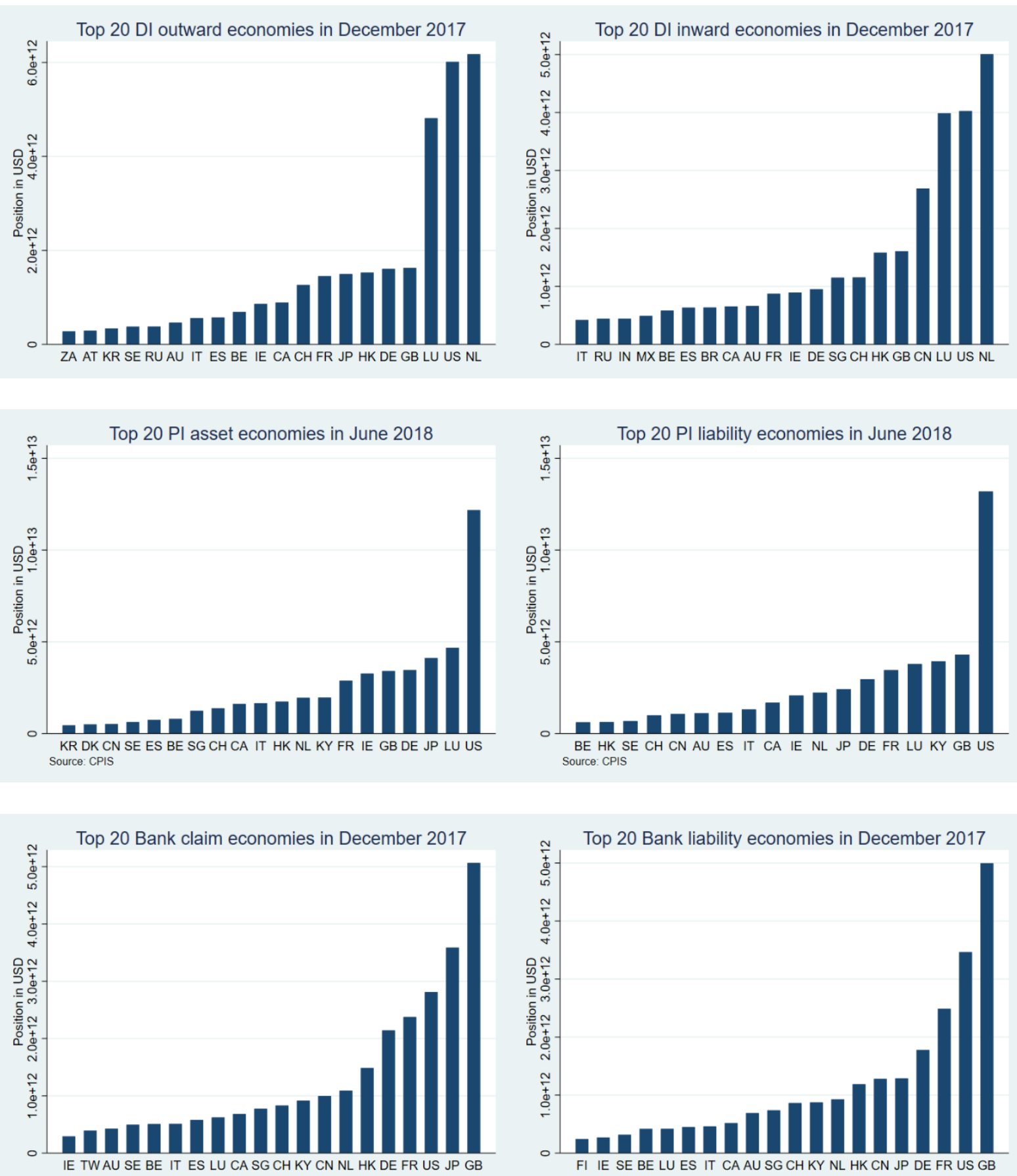

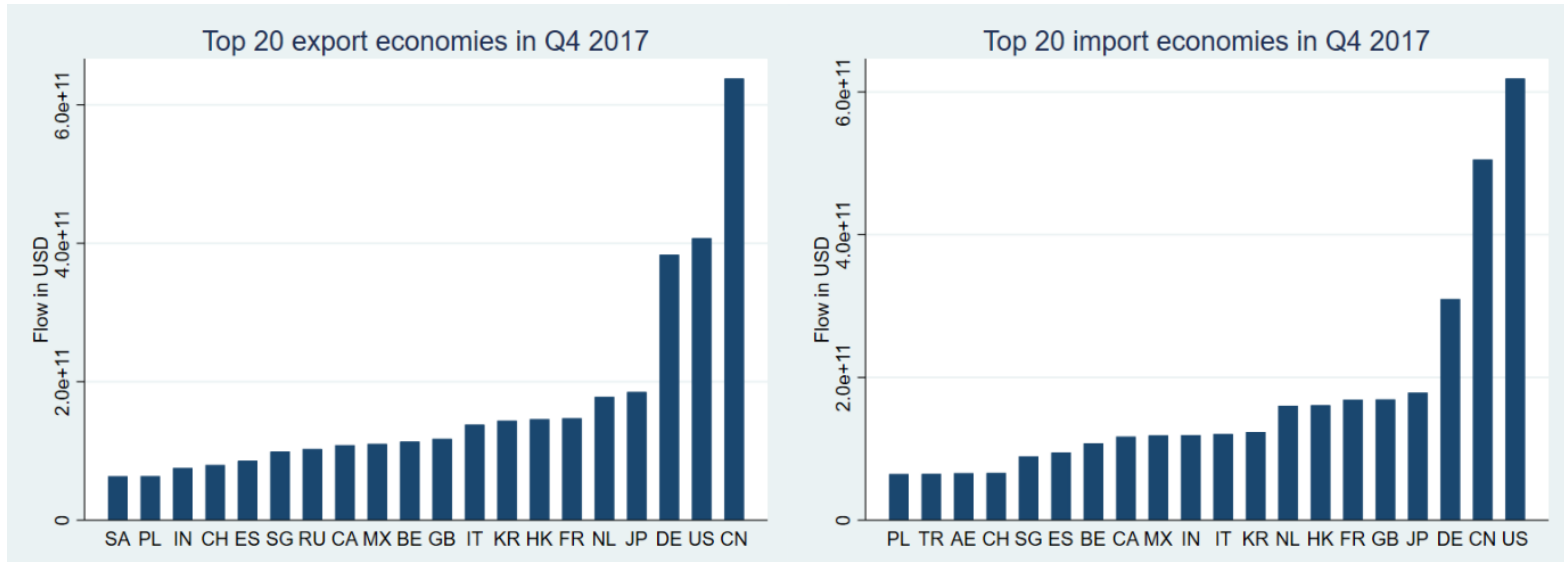

B. Correlation of U.S. international financial connections

Table 2. Correlation Matrix of the U.S. International Financial Connections in Log

\begin{tabular}{l|ccccccc}
\hline & $\begin{array}{c}\text { PI } \\
\text { asset }\end{array}$ & $\begin{array}{c}\text { Bank } \\
\text { asset }\end{array}$ & $\begin{array}{c}\text { Bank } \\
\text { liability }\end{array}$ & $\begin{array}{c}\text { DI } \\
\text { inward }\end{array}$ & $\begin{array}{c}\text { DI } \\
\text { outward }\end{array}$ & Export & Import \\
\hline PI asset & 1 & & & & & & \\
Bank asset & 0.87 & 1 & & & & & \\
Bank & 0.84 & 0.88 & 1 & & & & \\
liability & & & & & & & \\
DI inward & 0.88 & 0.81 & 0.83 & 1 & 1 & & \\
DI outward & 0.80 & 0.73 & 0.64 & 0.74 & 1 & \\
Export & 0.74 & 0.69 & 0.64 & 0.63 & 0.82 & 1 & 1 \\
Import & 0.73 & 0.62 & 0.65 & 0.66 & 0.68 & 0.91 & 1 \\
\hline
\end{tabular}

\section{Subplots of Figure 1 with ISO2 label for each date}

S1 means June and S2 means December.
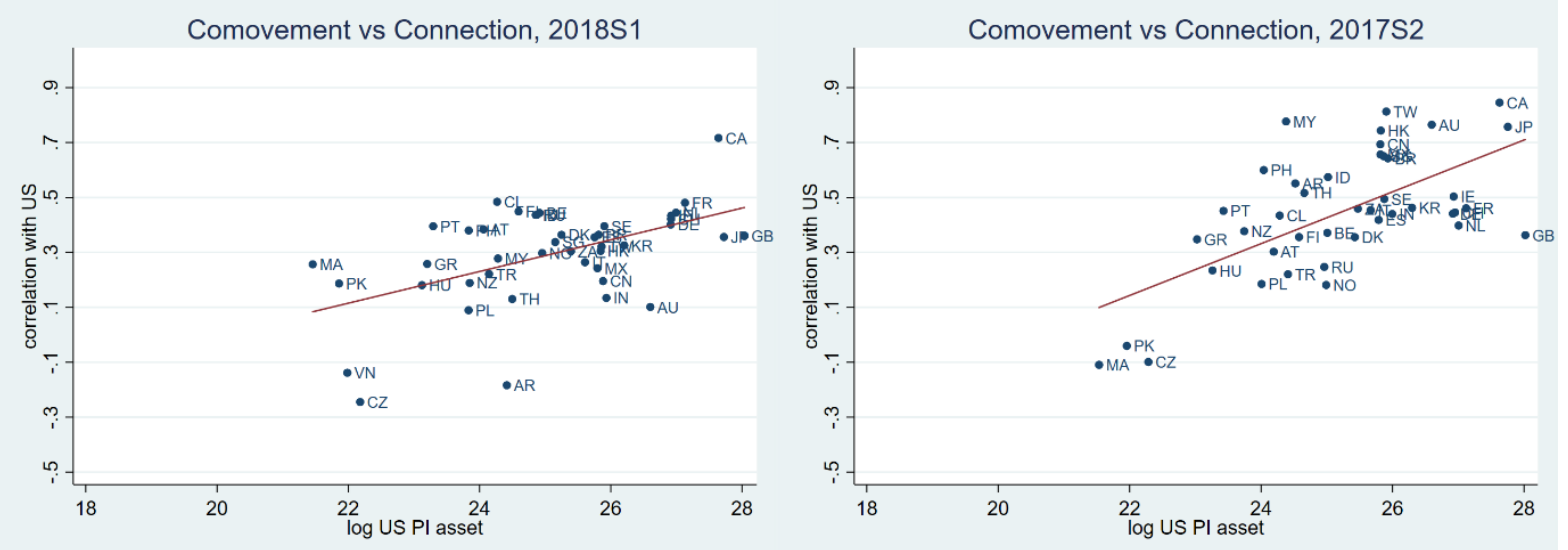

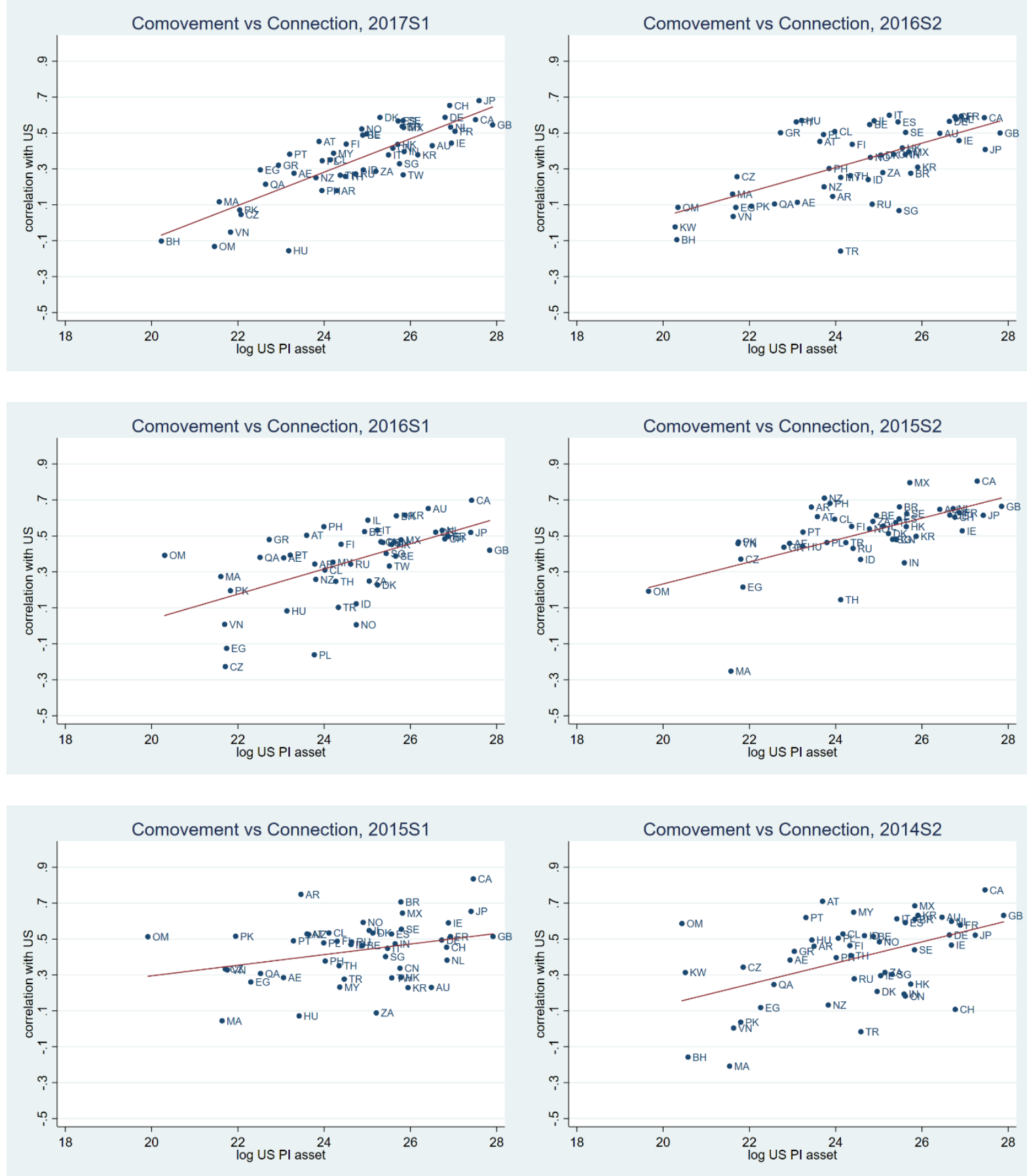

CInternational Monetary Fund. Not for Redistribution 

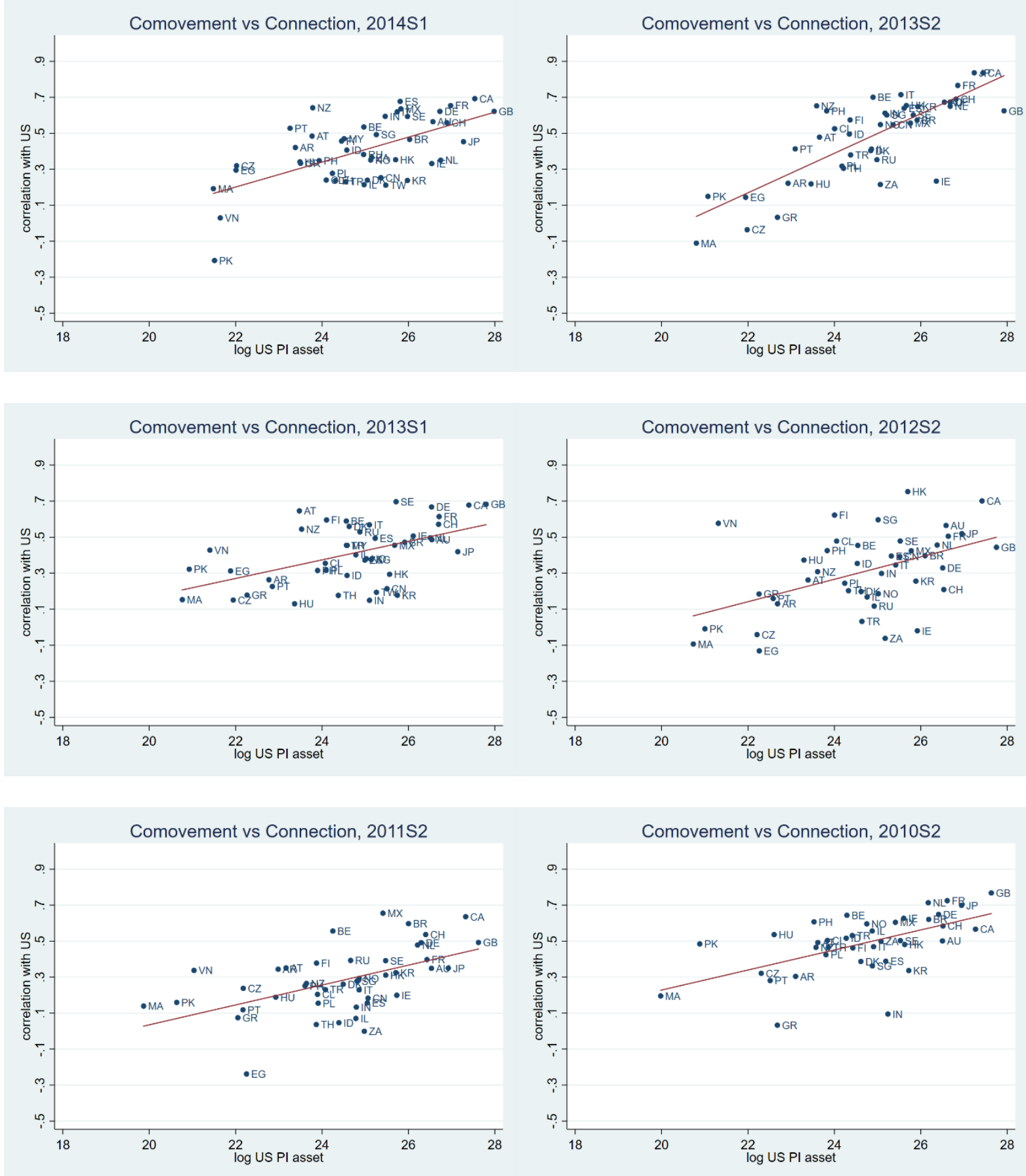

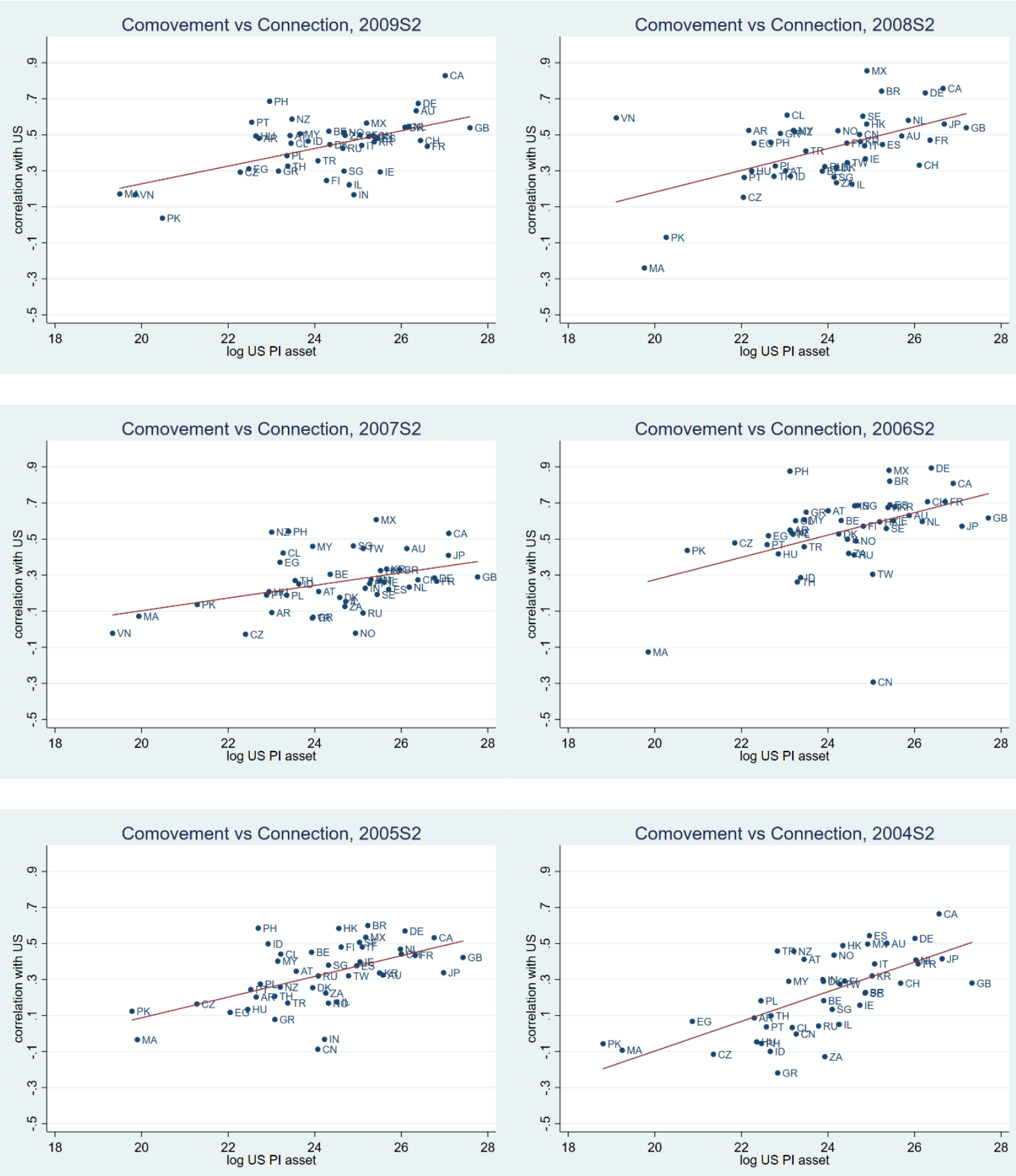

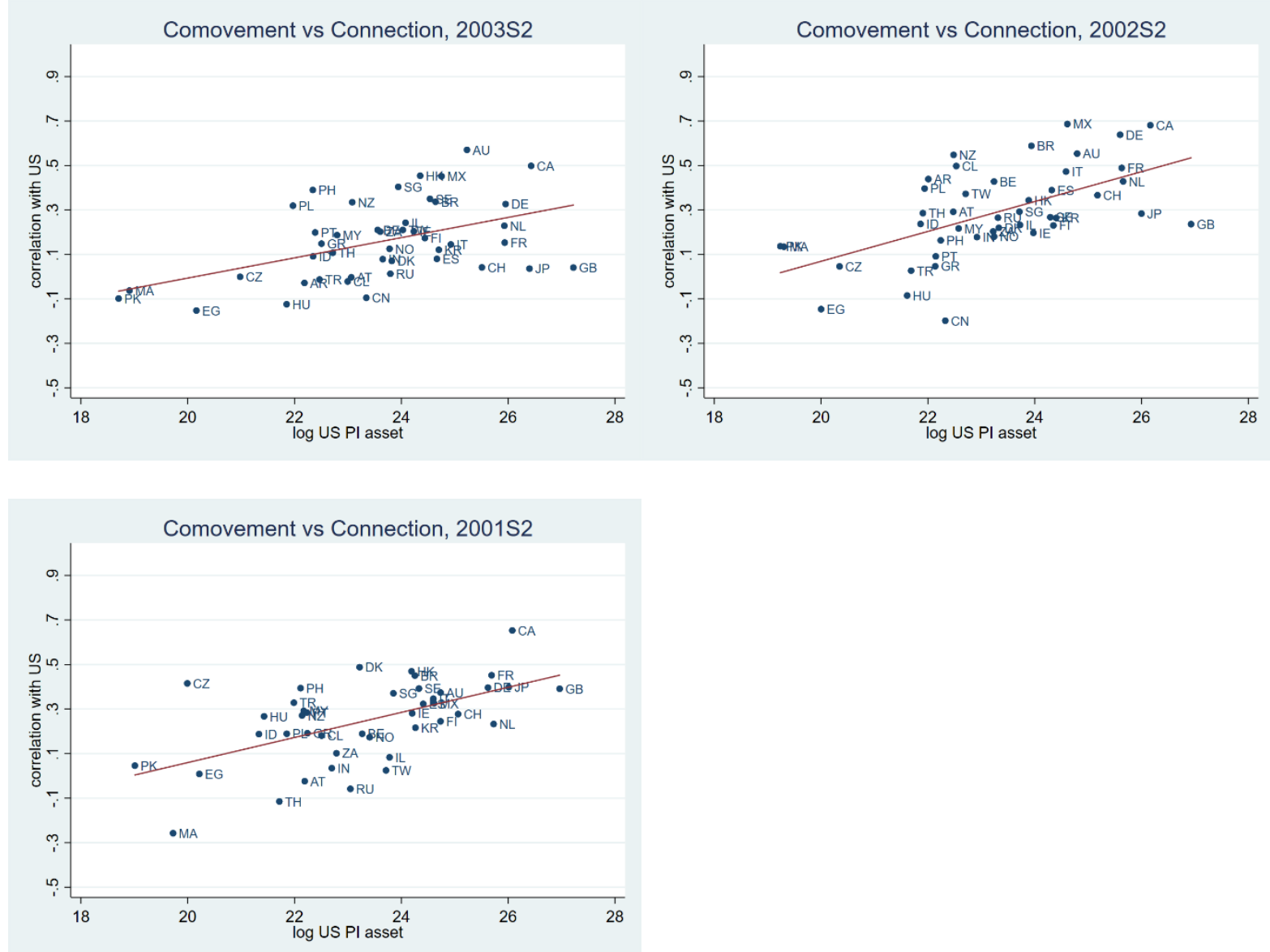
D. U.S. comovement vs connection, by economy

The relationship is weaker if Figure 1 is sliced by economy.

\section{Comovement vs Connection, by economy}

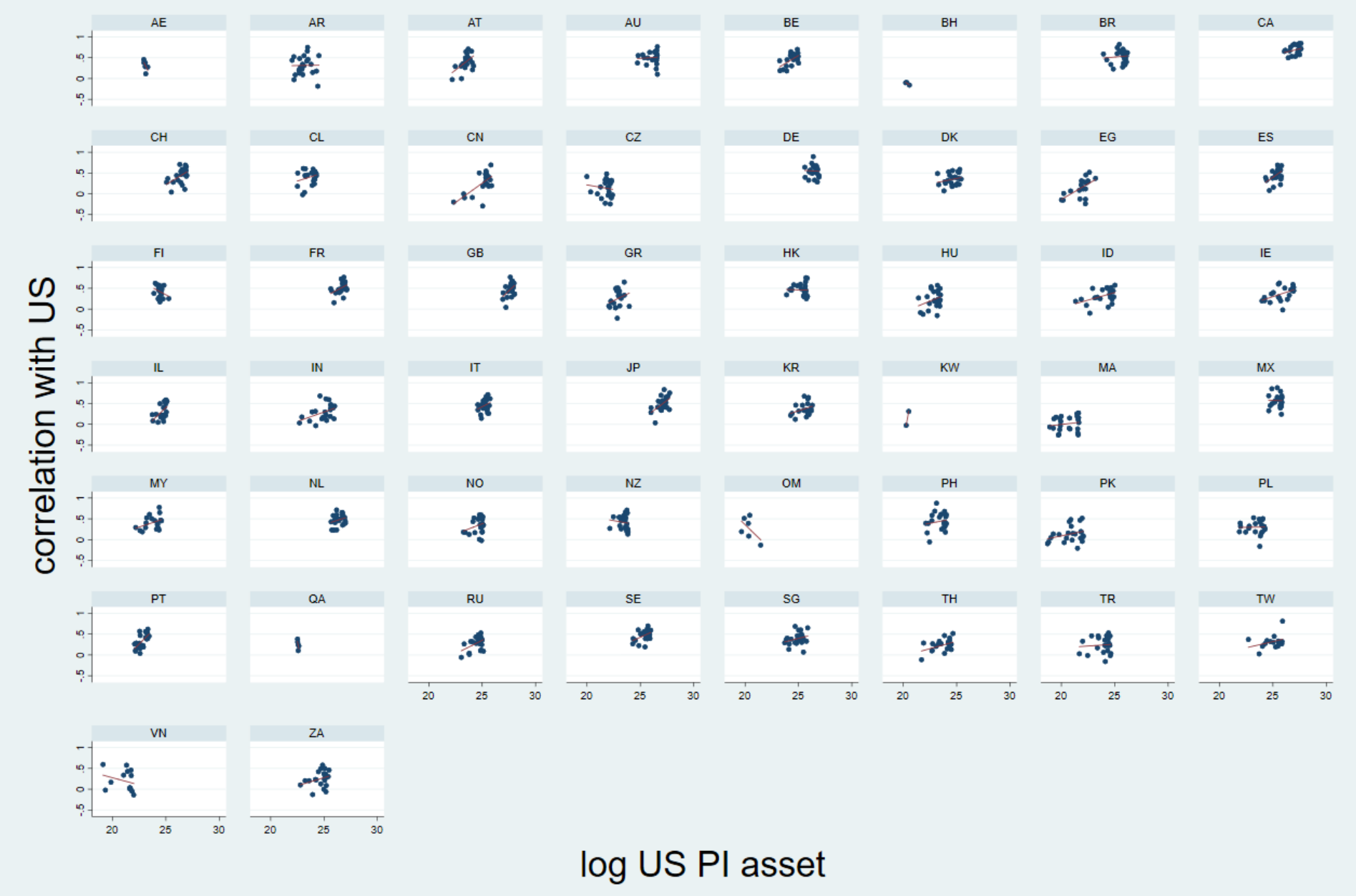




\section{E. 5 robustness checks of U.S. Comovement vs Connection}

(1) The pattern survives after considering daily FX return

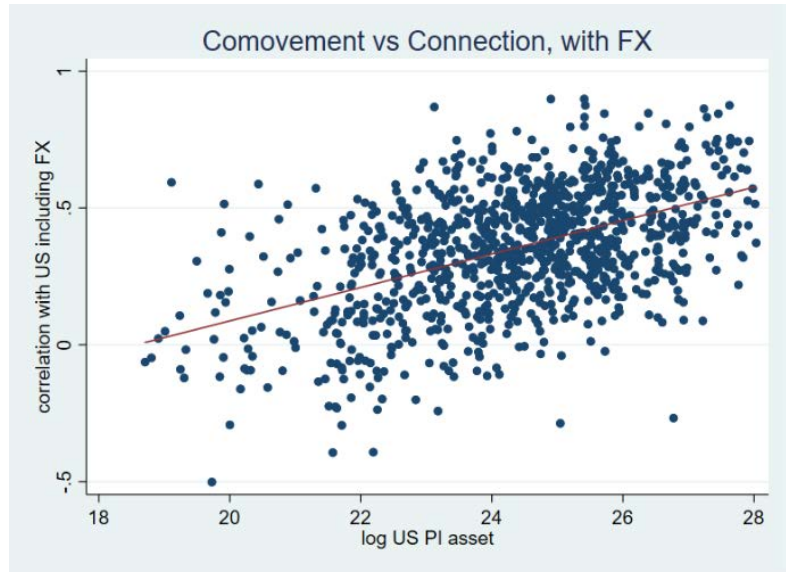

(2) The pattern survives after normalizing the position by the GDP of counterpart economy

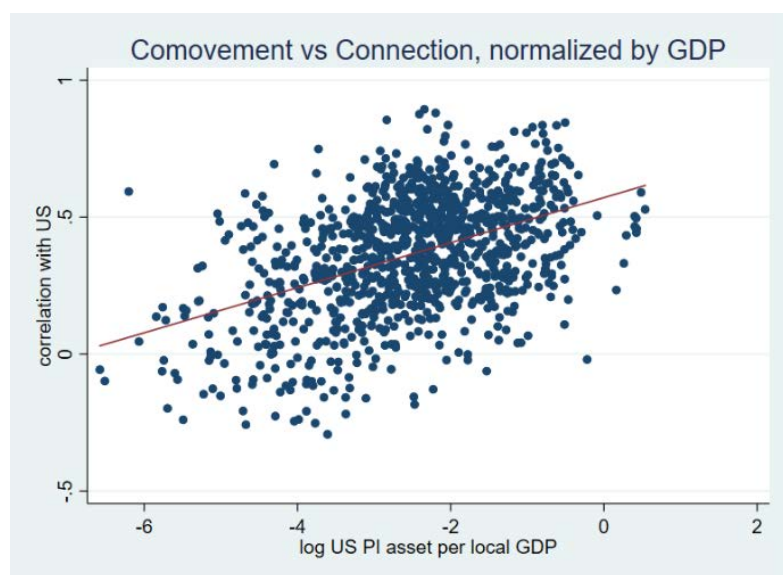

(4) The pattern survives if the connection variable is replaced by portfolio equity position or portfolio debt position.
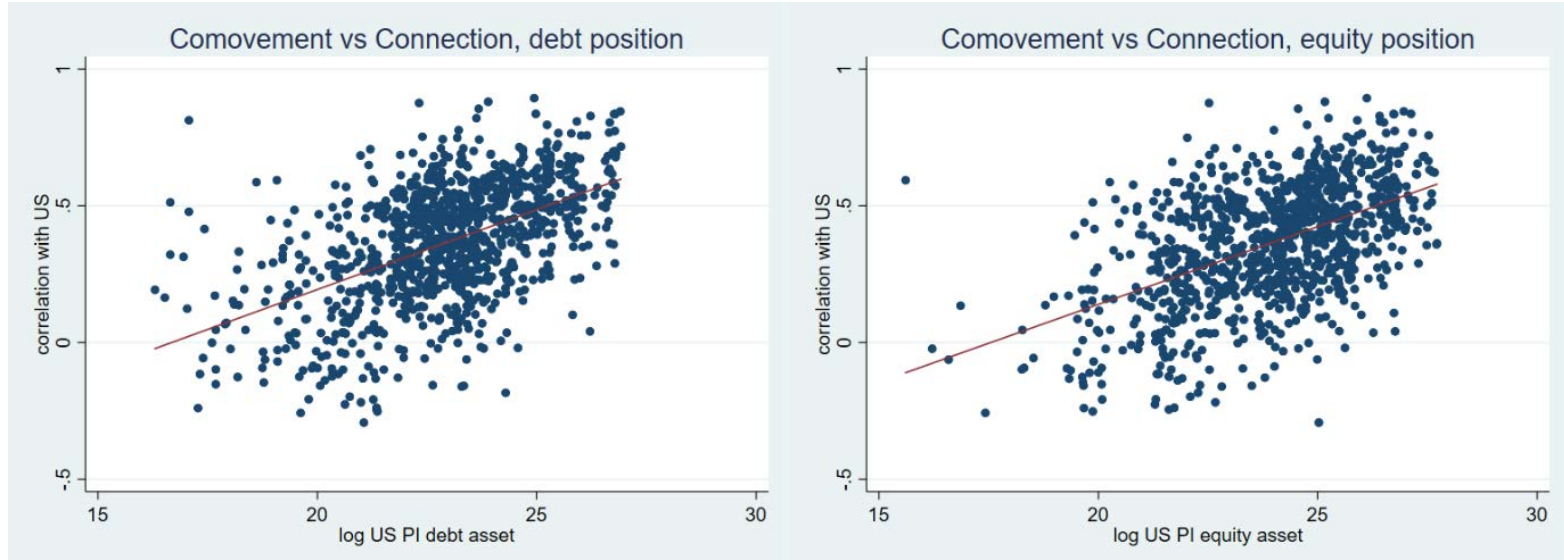
(4) The pattern survives after excluding dividend if the stock index is replaced by the price index that excludes dividends.

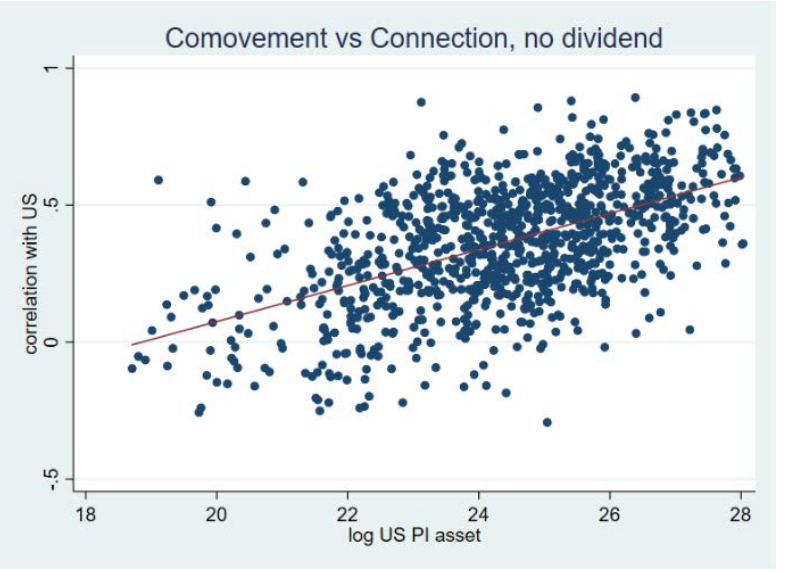

(5) The pattern survives if the time-lag-adjusted U.S. stock return is replaced by the current or max as discussed in section IV.B.
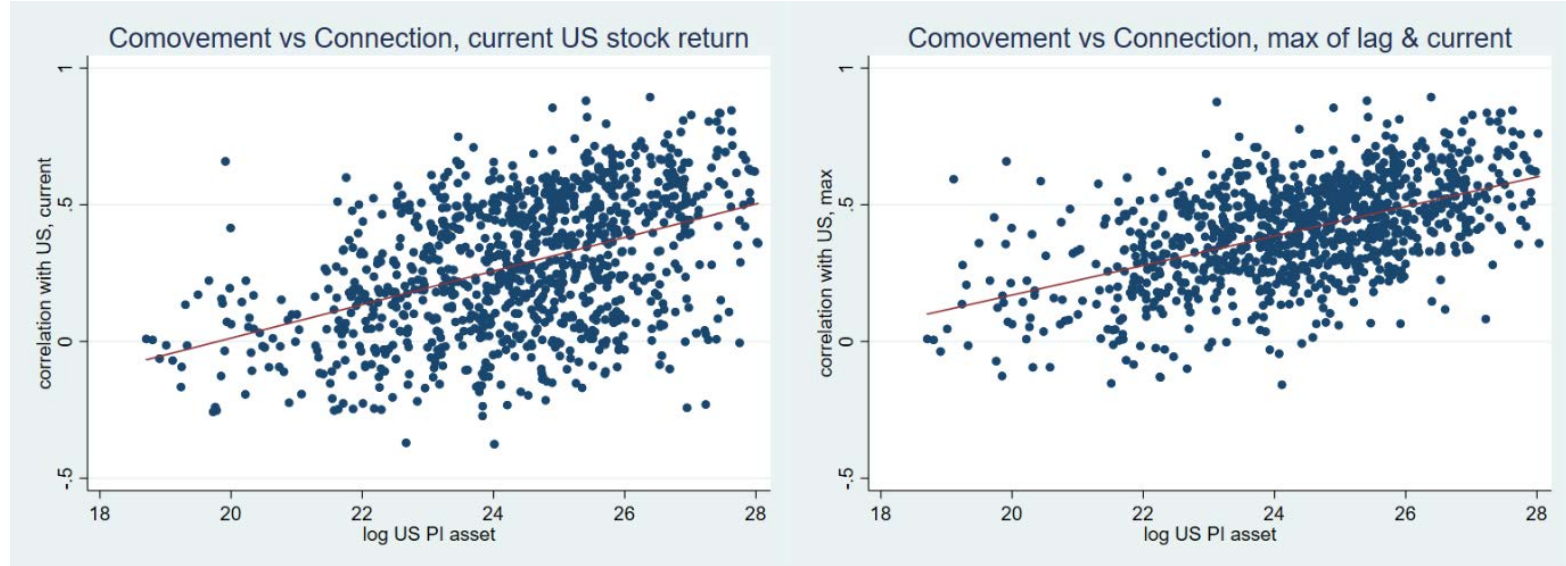


\section{F. Comovement vs Connection, top $6 R_{p}^{2}$ economies}

The 6 charts below show December 2017 data. Note that $R^{2}$ is calculated with time fixed effect, so the $R^{2}$ in the charts below does not equal to Table 1 .
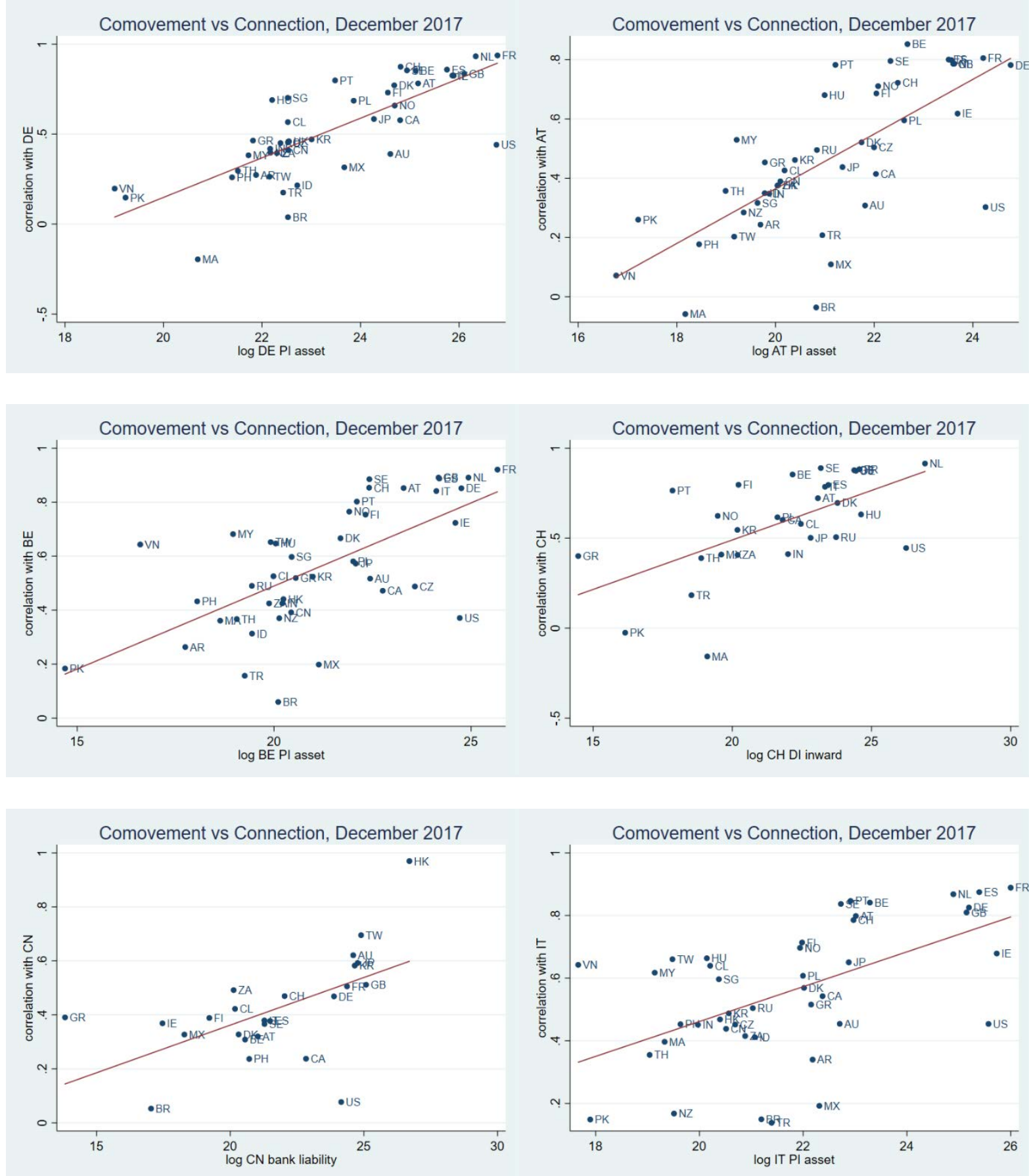